\title{
The signaling signature of the neurotensin type 1 receptor with endogenous ligands
}


Andrea Brumwell, Alexandre Murza, Jean-Michel Longpré, Éric Marsault $\frac{\mathrm{ORCID} \text { ID }}{\text {, Michel }}$ Grandbois, Philippe Sarret*, and Richard Leduc*ORCID ID

Department of Pharmacology-Physiology, Faculty of Medicine and Health Sciences, Institut de Pharmacologie de Sherbrooke, Université de Sherbrooke, Sherbrooke, Québec, Canada J1H 5N4

e-mail addresses of the authors:

Elie.Besserer-Offroy@USherbrooke.ca (ÉBO); Rebecca.Brouillette@USherbrooke.ca (RLB);

Sandrine.Lavenus@USherbrooke.ca $\quad$ (SL); $\quad$ Ulrike.Froehlich@USherbrooke.ca $\quad$ (UF);

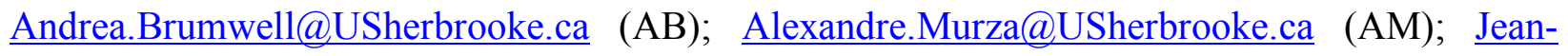

Michel.Longpre@,USherbrooke.ca $\quad(J M L) ; \quad$ Eric.Marsault@,USherbrooke.ca $\quad$ (ÉM);

Michel.Grandbois@USherbrooke.ca $\quad(\mathrm{MG}) ; \quad$ *Philippe.Sarret@,USherbrooke.ca $\quad$ (PS);

* Richard.Leduc@,USherbrooke.ca (RL)

\section{* Co-corresponding authors:}

Philippe Sarret, $\mathrm{PhD}$ and Richard Leduc, $\mathrm{PhD}$

Phone: +1 (819) 821-8000 ext. 75413

Fax: $+1(819)$ 564-5400 


\section{Abstract}

The human neurotensin 1 receptor (hNTS1) is a G protein-coupled receptor involved in many physiological functions, including analgesia, hypothermia, and hypotension. To gain a better understanding of which signaling pathways or combination of pathways are linked to NTS1 activation and function, we investigated the ability of activated hNTS1, which was stably expressed by $\mathrm{CHO}-\mathrm{K} 1$ cells, to directly engage $\mathrm{G}$ proteins, activate second messenger cascades and recruit $\beta$-arrestins. Using BRET-based biosensors, we found that neurotensin (NT), NT(8-13) and neuromedin $\mathrm{N}(\mathrm{NN})$ activated the $\mathrm{G \alpha}_{\mathrm{q}^{-}}, \mathrm{G \alpha}_{\mathrm{il}^{-}}, \mathrm{G \alpha}_{\mathrm{oA}^{-}}$, and $\mathrm{G \alpha}_{13}$-protein signaling pathways as well as the recruitment of $\beta$-arrestins 1 and 2. Using pharmacological inhibitors, we further demonstrated that all three ligands stimulated the production of inositol phosphate and modulation of cAMP accumulation along with ERK1/2 activation. Interestingly, despite the functional coupling to $\mathrm{G \alpha}_{\mathrm{i} 1}$ and $\mathrm{G} \alpha_{\mathrm{oA}}$, NT was found to produce higher levels of cAMP in the presence of pertussis toxin, supporting that hNTS1 activation leads to cAMP accumulation in a Gas-dependent manner. Additionally, we demonstrated that the full activation of ERK1/2 required signaling through both a PTX-sensitive $\mathrm{G}_{\mathrm{i} / \mathrm{o}}$-c-Src signaling pathway and PLC $\beta$-DAG-PKC-Raf-1dependent pathway downstream of $\mathrm{G}_{\mathrm{q}}$. Finally, the whole-cell integrated signatures monitored by the cell-based surface plasmon resonance and changes in the electrical impedance of a confluent cell monolayer led to identical phenotypic responses between the three ligands. The characterization of the hNTS1-mediated cellular signaling network will be helpful to accelerate the validation of potential NTS1 biased ligands with an improved therapeutic/adverse effect profile. 
This is the accepted (postprint) version of the following article: Besserer-Offroy É, et al. (2017). Eur J Pharmacol. doi: 10.1016/j.ejphar.2017.03.046, which has been accepted and published in its final form at http://www.sciencedirect.com/science/article/pii/S0014299917302157

Keywords: G protein-coupled receptor (GPCR); G protein; $\beta$-arrestin; Neurotensin receptor 1;

Neurotensin; Neuromedin N

\section{Chemical compounds studied in this article:}

Neurotensin (1-13) (PubChem CID: 25077406); Neurotensin (8-13) (PubChem CID: 5311318);

Neuromedin N (PubChem CID: 9940301); SR48692 (PubChem CID: 119192) 


\section{Introduction}

G protein-coupled receptors (GPCRs) constitute the largest superfamily of cell-surface proteins involved in signal transduction (Bockaert, 1999). A large and diverse group of ligands activates GPCRs, which transduce intracellular signals by coupling to $\mathrm{G}$ proteins or other proteins such as arrestins (Marinissen and Gutkind, 2001). Today, GPCRs are the targets of up to $40 \%$ of the total drug market and hence continue to be of great interest for the development of therapeutic agents.

Given that a GPCR can couple to different signaling pathways and that the latter can be selectively engaged or blocked led to the emergence of a novel paradigm called bias signaling (Kenakin, 2013). However, to fully exploit bias signaling, a clear profile of the signaling pathways activated by a GPCR is crucial. Here, we focused on deciphering the signaling signature of human NTS1 following stimulation by endogenous ligands. The neurotensin receptor family is composed of three subtypes, NTS1, NTS2, and NTS3 (Vincent et al., 1999). Among these subtypes, NTS1 (Tanaka et al., 1990; Vita et al., 1993) and NTS2 (Chalon et al., 1996; Mazella et al., 1996; Vita et al., 1998) belong to the rhodopsin-like family of GPCRs, whereas NTS3 belongs to the sortilin receptor family (Mazella and Vincent, 2006; Mazella et al., 1998). Since its discovery, NTS1 has been detected in peripheral tissues such as the vascular endothelium and gastrointestinal tract (Azriel and Burcher, 2001; Coppola et al., 2008) as well as in the central nervous system (CNS) (Roussy et al., 2008), suggesting that it is involved in a broad variety of physiological functions (Feng et al., 2015; Osadchii, 2015). Indeed, NTS1 mediates blood pressure lowering (Rioux et al., 1982), ileum contraction or relaxation (Carraway and Mitra, 1994), analgesia (Roussy et al., 2008), and hypothermia (Feifel et al., 2010). 
NTS1 is endogenously activated by neurotensin (NT) as well as by neuromedin N (NN), both of which are derived from the same pro-NT/NN precursor (Rostène and Alexander, 1997; Rovere et al., 1996). Structure-activity studies of NT have revealed that the minimal bioactive fragment corresponds to the C-terminal hexapeptide of NT, NT(8-13) (St-Pierre et al., 1981).

To date, depending on the cell type, NTS1 has been linked, through $G \alpha_{i,}, G \alpha_{\imath}$, and $G \alpha_{s}$ coupling, to a variety of intracellular signaling cascades including cyclic AMP (cAMP), inositol phosphate (IP), and arachidonic acid accumulation as well as the activation/inhibition of mitogen-activated protein kinases (ERK1/2 and JNK) and serine/threonine protein kinase Akt (Müller et al., 2011). Interestingly, NTS1-G protein interactions involve different receptor domains; interaction with $\mathrm{Ga}_{4 \mid 1}$ requires the intact third intracellular loop of the receptor, and coupling to $\mathrm{G} \alpha_{\text {s }}$ and $\mathrm{G} \alpha_{\mathrm{io}}$ involves the receptor's C-terminal domain (Gailly et al., 2000; Grisshammer and Hermans, 2001; Najimi et al., 2002; Skrzydelski et al., 2003). NT binding to NTS1 also induces the internalization of the receptor-ligand complex via a clathrin-dependent endocytic process requiring the recruitment of dynamin, intersectin, and $\beta$-arrestins to the GRK2/GRK5 phosphorylated receptor (Inagaki et al., 2015; Oakley et al., 2001; 2000; Savdie et al., 2006; Vandenbulcke et al., 2000; Zhang, 1999). Like many GPCRs, NTS1 internalization has been shown to lead to G proteinindependent signaling (Souazé et al., 1997; Toy-Miou-Leong et al., 2004). Although the coupling to diverse $G$ proteins has been demonstrated through the modulation of second messenger cascades, there is still no direct evidence of the interaction between NTS1 and G proteins in a unique cell type. 
This is the accepted (postprint) version of the following article: Besserer-Offroy É, et al. (2017). Eur J Pharmacol. doi: 10.1016/j.ejphar.2017.03.046, which has been accepted and published in its final form at http://www.sciencedirect.com/science/article/pii/S0014299917302157

In the present study, we used bioluminescence resonance energy transfer (BRET) biosensors and label-free whole-cell assays to study the ability of NT, NT(8-13) and NN to activate signaling pathways following their binding to hNTS1 expressed in CHO-K1 cells. 


\section{Materials and Methods}

\subsection{Materials}

Neurotensin 1-13 (NT), IBMX (3-isobutyl-1-methylxantine), SR48692, and forskolin were obtained from R\&D Systems, Inc. (Minneapolis, MN, USA). NT(8-13) was synthesized at the peptide synthesis facility of the Université de Sherbrooke. NN was purchased from GenScript USA Inc. (Piscataway, NJ, USA). Coelenterazine 400A (DeepBlueC) was purchased from Gold Biotechnology Inc. (St. Louis, MO, USA). The peptide sequences of NT, NT(8-13) and NN are shown in Table 1. Ham's F12, HEPES (4-(2-hydroxyethyl)-1-piperazineethanesulfonic acid), Penicillin-streptomycin-glutamine and fetal bovine serum (FBS) were obtained from Wisent (St. Bruno, QC, Canada), Opti-MEM was acquired from Invitrogen (Burlington, ON, Canada). Lance Ultra cAMP and pERK1/2 assay kits were purchased from Perkin Elmer (Montréal, QC, Canada). A Cisbio IP1 assay kit was purchased through Cedarlane (Burlington, ON, Canada). All inhibitors used in this study were from Santa-Cruz Biotechnologies (Dallas, TX, USA), with the exception of UBOQIC, which was purchased from Bonn University; Pertussis Toxin (PTX) which was purchased from List Biological Laboratories (Campbell, CA, USA); Dynasore, which was obtained from Tocris (Minneapolis, MN, USA); and Y27632, which was obtained from Cell Signaling Technology (Danvers, MA, USA).

\subsection{Plasmids and constructs}

The cDNAs encoding the human neurotensin receptor type 1 and the $G_{\beta 1}$ subunit were obtained from the Missouri S\&T cDNA Resource Center (Rolla, MO, USA). The fusion vector pIREShygro3-GFP10 and RlucII- $\beta$-arrestin 1 or 2 plasmids were kindly provided by Dr. Michel 
Bouvier (Dept. of Biochemistry and IRIC, Université de Montréal, Montréal, QC, Canada). Using an InFusion advantage PCR cloning kit (Clontech Laboratories, Mountain View, CA, USA), the hNTS1 construct was inserted into the pIREShygro3-GFP10 vector as previously described

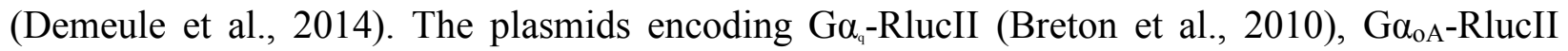
(Richard-Lalonde et al., 2013), Ga $\alpha_{13}$-RlucII (Demeule et al., 2014), G $\alpha_{i 1}$-RlucII, GFP10-G $\gamma_{1}$, and GFP10-G $\gamma_{2}$ (Galés et al., 2006) were kindly provided by Dr. Michel Bouvier. All constructs were verified by DNA sequencing.

\subsection{Cell culture and transfections}

CHO-K1 cells stably expressing hNTS1 (CHO-hNTS1 cells) were purchased from Perkin Elmer (Montréal, QC, Canada) and cultured in Ham's F12 containing 20 mM HEPES, 10\% FBS, 0.4 $\mathrm{mg} / \mathrm{ml} \mathrm{G} 418$, and penicillin (100 U/ml)-streptomycin (100 $\mu \mathrm{g} / \mathrm{ml})$-glutamine $(2 \mathrm{mM})$ under 5\% $\mathrm{CO}_{2}$ at $37^{\circ} \mathrm{C}$ in a humidified atmosphere. The $\mathrm{CHO}-\mathrm{K} 1$ cells were cultured in the same conditions as above but without G418. For the transient expression of recombinant proteins, T75 flasks were seeded with $3 \times 10^{6}$ cells, and $24 \mathrm{~h}$ later, the cells were transfected using PEI (Ehrhardt et al, 2006).

\subsection{BRET ${ }^{2}$ assay}

To monitor direct $G$ protein activation, we used the following biosensor couples: $G \alpha_{q}$-RlucII, GFP10-G $\gamma_{1}$, and $\mathrm{G} \beta_{1}$ (Breton et al., 2010); G $\alpha_{\circ A}-R l u c I I, ~ G F P 10-G \gamma_{1}$, and $\mathrm{G} \beta_{1}$ (Richard-Lalonde et al., 2013); $\mathrm{G} \alpha_{13}$-RlucII, GFP10-G $\gamma_{1}$, and $\mathrm{G} \beta_{1}$; or $\mathrm{G} \alpha_{i 1}$-RlucII, GFP10-G $\gamma_{2}$, and $\mathrm{G} \beta_{1}$ (Galés et al., 2006). G protein biosensors were transfected into CHO-hNTS1 cells. At $24 \mathrm{~h}$ post-transfection, the cells were detached with trypsin-EDTA and plated (50,000 cells/well) in white opaque 96-well 
plates (BD Falcon, Corning, NY, USA). At $48 \mathrm{~h}$ post-transfection, the cells were washed once with PBS, and $90 \mu \mathrm{L}$ of HBSS containing 20 mM HEPES was then added. Ligands were added at increasing concentrations for $20 \mathrm{~min}$ followed by coelenterazine-400A $(5 \mu \mathrm{M})$. The BRET ${ }^{2}$ measurements were collected in the 400 to $450 \mathrm{~nm}$ window (RlucII) and in the 500 to $550 \mathrm{~nm}$ window (GFP10) using the BRET² filter set on a GENios Pro plate reader (Tecan, Durham, NC, USA). The BRET ${ }^{2}$ ratio was determined as the light emitted by the acceptor GFP10 over the light emitted by the donor RlucII. The monitoring of $\beta$-arrestin recruitment was done by the transient transfection of CHO-K1 cells with plasmids containing cDNAs encoding hNTS1-GFP10 and RlucII- $\beta$-arrestin 1 or 2 . The same protocol as the one used for $\mathrm{G}$ protein activation was then used.

\subsection{IP-One and Lance Ultra cAMP assays}

The IP-One assay was performed according to the manufacturer's recommendations. Briefly, 15,000 CHO-hNTS1 cells per well (384-well shallow well plate) were treated with increasing concentrations of NT, NT (8-13), or NN for $30 \mathrm{~min}$. IP1-d2 and anti-IP1-Cryptate were added for at least $1 \mathrm{~h}$. The plates were read on a GENios Pro plate reader with HTRF filters (excitation at $320 \mathrm{~nm}$ and emission at 620 and $665 \mathrm{~nm}$ ). The TR-FRET ratio was determined as the fluorescence of the acceptor $(665 \mathrm{~nm})$ over the fluorescence of the donor $(620 \mathrm{~nm})$. The Lance Ultra cAMP assay was performed according to the manufacturer's recommendations. Briefly, 1,000 cells per well (384-well shallow well plate) were treated with increasing concentrations of NT, NT(8-13), or $\mathrm{NN}$ for $30 \mathrm{~min}$ in the presence or absence of $1 \mu \mathrm{M}$ forskolin. cAMP-tracer and anti-cAMPCryptate were added for at least $1 \mathrm{~h}$. The plates were read on a GENios Pro plate reader with HTRF filters, and the TR-FRET ratio was calculated as described for the IP-One assay. 


\subsection{AlphaScreen assay}

ERK1/2 phosphorylation in the CHO-hNTS1 cells was monitored with Perkin Elmer's AlphaScreen SureFire assays as previously described (Koole et al., 2010). Cells were seeded in 96-well plates. Twenty-four hours later, the cells were serum-starved overnight. For concentrationresponse curves, the cells were stimulated for 10 min with increasing concentrations of NT, NT(813), or NN. For time-course curves, the cells were incubated with inhibitors as mentioned in the figure legend and stimulated for $0,5,10,15,30,45$, and 60 min with $1 \mu \mathrm{M}$ NT. The cells were then lysed with $20 \mu \mathrm{L}$ of $5 \mathrm{X}$ lysis buffer, incubated at room temperature for $10 \mathrm{~min}$ on a plate shaker, and frozen overnight at $-20^{\circ} \mathrm{C}$. A total of $5 \mu \mathrm{L}$ of the lysate was used for analysis. The readings were performed on a Perkin Elmer EnSpire 2300 multilabel reader.

\subsection{Whole-cell integrated response quantification}

The measurements of the cell monolayer resistivity were performed in cysteine-stabilized, PolyL-Lysine-coated 96-well plates (96w20idf from Applied Biophysics, Troy, NY, USA) as recommended by the manufacturer. A total of 30,000 CHO-hNTS1 cells were plated into each well and allowed to grow for $24 \mathrm{~h}$ in serum-containing media before being serum-starved for 16 to $18 \mathrm{~h}$ prior to the experiment. On the day of the experiment, the cells were washed with PBS, and $90 \mu \mathrm{L}$ of Leibovitz's L-15 modification medium (L15; Wisent, St-Bruno, QC, Canada) was then added per well. The biophysical parameters (electrical resistance at a $4000 \mathrm{~Hz}$ single frequency) of the cell monolayer were recorded with an ECIS Z $\theta$ linked to a 96-well array station (Applied Biophysics, Troy, NY, USA) for 60 min prior to stimulation with NT, NT(8-13) or NN at $1,10,100$ or $1000 \mathrm{nM}$ or in the presence of the NTS1 receptor antagonist SR48692 at $10 \mu \mathrm{M}$. 
The whole-cell integrated behaviors were then monitored for a total of 180 min following stimulation.

Two days before surface plasmon resonance (SPR) detection, the cells were seeded into each well containing the SPR substrate (the preparation of the SPR substrate was described by Cuerrier et al., (2008) at a density of 100,000 cells $/ \mathrm{cm}^{2}$ and serum-starved the following day. Before the SPR signal was measured, the cells were washed twice with L15 medium and transferred to the SPR apparatus. Ninety percent confluency, as evaluated by contrast microscopy, is necessary in order to perform the experiment. The SPR analysis was performed at $37^{\circ} \mathrm{C}$ on a custom-built surface plasmon resonance apparatus as previously described (Chabot et al., 2009; Cuerrier et al., 2008).

\subsection{Data analysis}

The $\mathrm{EC}_{50}$ values of the $\mathrm{BRET}^{2}$, IP-One, Lance Ultra cAMP, AlphaScreen, and whole-cell integrated response assays were determined as the concentration of ligand showing $50 \%$ of activation. The data were calculated using concentration-response three parameters non-linear regression of GraphPad Prism 6 (La Jolla, CA, USA). The experimental numbers are described in each figure legend.

The half-times for $\beta$-arrestin recruitment were obtained using the one-phase association exponential regression in GraphPad Prism 6 and are represented as the half-time \pm S.E.M. of 3 independent experiments, each done in triplicate.

Electrical resistivity traces are the averaged normalized response values \pm S.E.M. of at least 3 separate experiments. The normalized response was calculated as the resistivity of the cell monolayer divided by the average resistivity during the $60 \mathrm{~min}$ baseline. The whole-cell integrated 
This is the accepted (postprint) version of the following article: Besserer-Offroy É, et al. (2017). Eur J Pharmacol. doi: 10.1016/j.ejphar.2017.03.046, which has been accepted and published in its final form at http://www.sciencedirect.com/science/article/pii/S0014299917302157

concentration-response curve was generated using the maximum value of the normalized response for each ligand concentration.

SPR traces are the averaged normalized reflectance values \pm S.E.M. of at least 6 separate experiments. The normalized reflectance was calculated as the reflectance value at a specified time minus the reflectance value at the beginning of the experiment.

Statistical analyses were performed using GraphPad Prism 6 and are described in the figure legend when applicable. A value was considered statistically significant when $\mathrm{P}<0.05$.

(c) 2017. This manuscript version is made available under the CC-BY-NC-ND 4.0 license http://creativecommons.org/licenses/by-nc-nd/4.0/ 


\section{Results}

\subsection{Agonist-dependent hNTS1 activation of $G \alpha_{q}, G \alpha_{i}, G \alpha_{o}$, and $G \alpha_{13}$}

To elucidate the signaling signature of hNTS1 following its binding with NT, NT(8-13), or NN (sequences provided in Table 1), we initially assessed the ability of the receptor to couple to various $\mathrm{G}$ proteins using BRET biosensors in CHO-K1 cells stably expressing the receptor. We first determined the ability of hNTS1 to activate $\mathrm{G \alpha}_{\mathrm{q}}$ by measuring the dissociation of $\mathrm{G \alpha}_{\mathrm{q}}$-RlucII and GFP10-G $\gamma_{1}$. NT, NT(8-13), and NN promoted a decrease in the BRET ${ }^{2}$ ratio, confirming the activation of $\mathrm{G} \alpha_{\mathrm{q}}$ by stimulated hNTS1 receptors (Fig. 1A). The activation of $\mathrm{G \alpha}_{\mathrm{q}}$ by NT, NT(813), and $\mathrm{NN}$ was found to be concentration dependent, and the $\mathrm{EC}_{50}$ values are shown in Table 2. These results are in agreement with the potencies previously observed in the NTS1/G $\alpha_{q}$-related second messenger assays (Choi et al., 1999; Kitabgi et al., 1986). Since several studies have shown that NT-induced arachidonic acid production was dependent on the PTX-sensitive Ga $\alpha_{\mathrm{i} / \mathrm{o}}$ pathway (Gailly et al., 2000; Najimi et al., 2002), we further investigated whether NTS1 promoted the engagement of $\mathrm{G} \alpha_{\mathrm{il}}$ and $\mathrm{G} \alpha_{\mathrm{OA}}$ in a similar experimental paradigm as the one used for $\mathrm{G} \alpha_{\mathrm{q}}(\mathbf{F i g .} \mathbf{1 B}$, C; Table 2). Our results show that all three ligands activated both $\mathrm{G} \alpha_{\mathrm{il}}$ and $\mathrm{G} \alpha_{\mathrm{OA}}$. To further study the signaling signature of hNTS1, we also assessed the ability of these three ligands to promote the activation of $\mathrm{G \alpha}_{13}$, which is known to modulate small GTPase RhoA activity (Offermanns, 2003). By measuring the dissociation between G $\alpha_{13}$-RlucII and GFP10-G $\gamma_{1}$, we found that NT, NT(8-13), and NN promoted the activation of $\mathrm{G}_{13}$ (Fig. 1D, Table 2). The concentration-response curves revealed dose-dependent activation of $\mathrm{G}_{13}$ by NT, NT(8-13), and NN. Altogether, these results reveal for the first time the ability of hNTS1 to directly activate the $\mathrm{G \alpha}_{\mathrm{q}^{-}}, \mathrm{G \alpha}_{\mathrm{i}^{-}}, \mathrm{G}_{\mathrm{oA}}$, and G $\alpha_{13}$-mediated signaling pathways.

(c) 2017. This manuscript version is made available under the http://creativecommons.org/licenses/by-nc-nd/4.0/ 


\subsection{Downstream G protein signaling reveals functional coupling with $G \alpha_{q}, G \alpha_{s}$, and $G \alpha_{i}$}

To corroborate the results observed with the BRET-based assays, we monitored downstream signaling events by quantifying the production of second messengers generated by hNTS1 activation. For the $\mathrm{G}_{\mathrm{q}}$ pathway, we tested the ability of NT, NT(8-13), and NN to stimulate the inositol phosphate (IP) cascade by measuring IP1 accumulation over 30 min (Fig. 2A). Interestingly, NT(8-13) was more potent than NT and NN at activating the IP signaling pathway (Fig. 2A; Table 2). Moreover, the use of UBOQIC, a $\mathrm{G} \alpha_{q}$ blocker (Inamdar et al., 2015) completely abolished the NT-induced increase in inositol phosphate formation (Fig. 2B), thus reinforcing the point that NT-induced calcium release is mediated solely through $\mathrm{G \alpha}_{\mathrm{q}}$ activation. Since NTS1 was found to potentiate the adenylyl cyclase-dependent production of cAMP through Gas activation (Skrzydelski et al., 2003; Yamada et al., 1993), we evaluated the ability of these three NTS1 ligands to produce cAMP over a 30-min stimulation period (Fig. 2C). All three ligands elevated the cAMP levels, but no differences were observed for the three compounds with respect to their $\mathrm{EC}_{50}$ values (Table 2). The production of cAMP is usually related to the activation of $\mathrm{G}_{\mathrm{s}}$, while $\mathrm{G}_{\mathrm{i} / \mathrm{o}}$ is known to inhibit cAMP production by adenylyl cyclase. However, there is also evidence that NTS1 may trigger a $\mathrm{G} \alpha_{s}$-independent increase in cAMP levels through $\mathrm{G \alpha}_{\mathrm{q} / 11^{-}}$ mediated activation of calcium-dependent adenylyl cyclase (Carraway and Mitra, 1998). In our model, we found that the $\mathrm{G} \alpha_{\mathrm{q}}$ blocker UBOQIC did not inhibit NT-induced cAMP production, therefore reinforcing the role played by $\mathrm{G} \alpha_{s}$ in cAMP accumulation (Fig. 2D).

To further understand the role of $\mathrm{G} \alpha_{\mathrm{i} / \mathrm{o}}$ in the cell's cAMP levels, we next examined the effect of blocking $\mathrm{G}_{\mathrm{i} / \mathrm{o}}$ function on the NT-induced cAMP accumulation by treating the cells with PTX. PTX is a toxin known to interfere on the G $\alpha_{\mathrm{i} / \mathrm{o}}$ pathway by an ADP-ribosylation of the Ga subunit 
resulting in a loss of the ability of this subunit to dissociate from the G $\beta \gamma$ dimer, thus, uncoupling the receptor form the $\mathrm{G}_{\mathrm{i} / \mathrm{o}}$ proteins(Mangmool and Kurose, 2011). Strikingly, NT was found to produce higher levels of cAMP in the presence of PTX (Fig. 2D). These results thus suggest that hNTS1 is functionally coupled to $\mathrm{G} \alpha_{\mathrm{i} / \mathrm{o}}$ but that the $\mathrm{G} \alpha_{\mathrm{s}}$-induced cAMP production observed following NT treatment counteracts the PTX-sensitive decrease in cAMP formation.

\section{3 hNTS1 activation leads to the recruitment of $\beta$-arrestins 1 and 2}

Given the predominant role played by $\beta$-arrestins in GPCR desensitization and internalization as well as G protein-independent signaling (Pierce and Lefkowitz, 2001; Premont and Gainetdinov, 2007), we further monitored the ability of hNTS1 to recruit $\beta$-arrestins 1 and 2 following receptor activation. Indeed, it had been previously reported that hNTS1 recruits $\beta$-arrestins after NT stimulation (Oakley et al., 2001; 2000); however, both the $\beta$-arrestin recruitment kinetics and potencies were never quantified. We thus used a BRET-based assay to measure the recruitment of $\beta$-arrestins 1 and 2 to the activated receptor in the CHO-K1 cells expressing hNTS1. We first performed time-course experiments to assess the dynamics of $\beta$-arrestin recruitment to hNTS1 (Fig. 3A, B). Our results reveal that NT, NT(8-13) and NN promoted rapid BRET ${ }^{2}$ increases between hNTS1-GFP10 and RlucII- $\beta$-arrestin 1 or 2 , which indicates $\beta$-arrestin recruitment to the hNTS1 receptor. For both $\beta$-arrestins, the time required for NT, NT(8-13), and NN to reach a maximal signal was equivalent, and this maximal response was sustained over time. The recruitment of $\beta$-arrestin 1 following NT, NT(8-13), or NN stimulation was completed with half times of $61.6 \pm 5.9 \mathrm{~s}, 61.5 \pm 7.9 \mathrm{~s}$, and $64.9 \pm 8.8 \mathrm{~s}$, respectively. $\beta$-arrestin 2 recruitment induced through NTS1 activation by NT, NT(8-13), or NN was accomplished in half times of $54.8 \pm 8.2 \mathrm{~s}$, $76.5 \pm 11.9 \mathrm{~s}$, and $104 \pm 20 \mathrm{~s}$, respectively. The recruitment of $\beta$-arrestin 1 induced by NTS1 
activation was found to be concentration-dependent (Fig. 3C), and the $\mathrm{EC}_{50}$ values are summarized in Table 2. NT and NT(8-13) were also found to induce $\beta$-arrestin 2 recruitment with a higher potency than NN (Fig. 3D; Table 2). Given the role of $\beta$-arrestins in receptor endocytosis, our results on $\beta$-arrestin 1 and 2 recruitment suggest that NT, NT(8-13), and NN will lead to hNTS1 receptor endocytosis (Claing et al., 2002; Ferguson et al., 1996).

\section{4 hNTS1 activates ERK1/2 through distinct G protein families}

We next investigated whether NT, NT(8-13), or NN induced the activation of ERK1/2 upon hNTS1 stimulation in our cellular model. Therefore, CHO cells stably expressing hNTS1 were stimulated with increasing concentrations of NT, NT(8-13), or NN for 10 min prior to the addition of lysis buffer. As shown in Fig. 4A, NT, NT(8-13), and NN promoted ERK1/2-phosphorylation in a concentration-dependent manner, and the $\mathrm{EC}_{50}$ values are reported in Table 2. Since ERK1/2 activation can occur through several intracellular mechanisms depending on receptor and cell type, we further investigated the contributions of signaling via $\mathrm{G}$ protein dependent and independent pathways to the activation of the ERK pathway.

To this end, we used different pharmacological inhibitors to determine which downstream signaling pathways mediate the hNTS1 stimulation-induced ERK1/2 phosphorylation. Since several studies have reported that GPCRs may mediate ERK1/2 activation through an EGFR transactivation-dependent mechanism (Overland and Insel, 2015), we first assessed whether the cell-permeable potent selective EGFR inhibitor PD168393 would decrease ERK1/2 phosphorylation. Our results revealed that EGFR inhibition did not change the ERK1/2 phosphorylation profile when compared to untreated cells, thereby suggesting that EGFR transactivation is not involved in ERK1/2 activation in our cellular model (Fig. 4B). Recent 
evidence also suggests that $\beta$-arrestins can act as signal transduction scaffolds for ERK1/2 activation following agonist-stimulated receptor internalization (Reiter and Lefkowitz, 2006). We thus examined if the use of dynasore, a small molecule GTPase inhibitor that targets dynamin and blocks endocytosis, could lead to a decrease in ERK1/2 phosphorylation (Fig. 4B). We did not observe significant changes in NT-induced ERK1/2 activation in the presence of dynasore, suggesting that NTS1-induced ERK1/2 phosphorylation is not dependent on $\beta$-arrestin internalization.

We next investigated the contributions of the $\mathrm{G} \alpha_{13}, \mathrm{G} \alpha_{\mathrm{q}}$ and $\mathrm{G} \alpha_{\mathrm{i} / \mathrm{o}}$, proteins to the hNTS1-mediated activation of the ERK1/2 pathway. The involvement of $\mathrm{G} \alpha_{13}$ in ERK1/2 phosphorylation was determined by exposing the CHO-K1 cells expressing hNTS1 to a 30 min pretreatment with 10 $\mu \mathrm{M}$ Y27632, a cell-permeable and highly selective inhibitor of $\mathrm{G} \alpha_{13}$-induced Rho-associated kinases (ROCK) activation (Narumiya et al., 2000). No significant differences in ERK1/2 phosphorylation were detected following Y27632 pretreatment (Fig. 4B). We next used the UBOQIC blocker and the potent PKC inhibitor Gö6983 to evaluate the roles of $\mathrm{G}_{\mathrm{q}}$ protein and the subsequent downstream phospholipase $C \beta$-DAG-PKC pathway, respectively, in ERK1/2 activation. Both inhibitors were found to reduce the long-lasting effect of NT on ERK1/2 phosphorylation, suggesting that hNTS1-induced ERK1/2 activation involves the sequential activation of $\mathrm{G \alpha}_{\mathrm{q}}$ and PKC (Fig. 4C).

Finally, GPCRs are capable of inducing ERK1/2 activation via PTX-sensitive G proteins with Src kinase and $\mathrm{G} \beta / \gamma$-dependent mechanisms (Rozengurt, 2007). The contribution of $\mathrm{G} \alpha_{\mathrm{i} / \mathrm{o}}$ protein to hNTS1-mediated ERK1/2 activation was therefore determined following an overnight pretreatment with PTX as a $\mathrm{Ga}_{\mathrm{i} / \mathrm{o}}$ blocking agent. Despite the demonstration that hNTS1 triggered ERK1/2 activation through $\mathrm{G}_{\mathrm{q}}$ (Fig. 4C), a complete loss of ERK1/2 phosphorylation was 
observed in PTX-treated cells (Fig. 4D), thus highlighting the key role for $\mathrm{G}_{\mathrm{i} / \mathrm{o}}$ in NT-induced ERK1/2 activation. Since PTX pretreatment induces ADP-ribosylation of $\mathrm{G}_{\mathrm{i} / \mathrm{o}}$ proteins and locks them into their inactive heterotrimeric conformation, we then evaluated whether $\mathrm{G} \alpha_{\mathrm{i} / \mathrm{o}}$-mediated ERK $1 / 2$ activation was induced by a $\mathrm{G} \beta / \gamma$-dependent mechanism by treating cells with gallein, a G $\beta / \gamma$ signaling inhibitor (Bonacci et al., 2006; Smrcka, 2013). No differences in the ERK1/2 phosphorylation rate between gallein-treated and untreated cells were recorded, suggesting that NT-induced ERK1/2 activation is mediated by $\mathrm{G}_{\mathrm{i} / \mathrm{o}}$ activity and not by $\mathrm{G} \beta / \gamma$-mediated signaling (Fig. 4D). We finally tested whether $\mathrm{G} \alpha_{\mathrm{i} / 0}$-induced ERK1/2 activation was mediated through downstream activation of the proto-oncogene tyrosine-protein kinase c-Src. This non-receptor tyrosine kinase can be activated by $\mathrm{G} \alpha_{\mathrm{i} /}$ and leads to ERK1/2 activation through direct phosphorylation of Ras/Raf or by indirect activation that involves EGFR transactivation (D. K. Luttrell and L. M. Luttrell, 2004; New and Wong, 2007; Piiper and Zeuzem, 2004). As shown in Fig. 4D, the inhibition of c-Src by a 30-min pretreatment with $1 \mu \mathrm{M}$ PD166285, a non-selective c-Src and receptor tyrosine kinase inhibitor (Panek et al., 1997), resulted in a loss of more than $75 \%$ of the ERK1/2 activation as well as in the appearance of a delay in the ERK1/2 phosphorylation rate. Since we had previously demonstrated that ERK1/2 phosphorylation was independent of EGFR activation, the results obtained with PD166285 suggest that in our cellular model, hNTS1-mediated ERK1/2 activation may result from direct c-Src activation by $\mathrm{G} \alpha_{\mathrm{i} / \mathrm{o}}$.

\subsection{Whole-cell integrated responses following hNTS1 activation}

Because NTS1 activates several signaling pathways, we next used impedance-based cell monitoring approach to monitor and quantify the whole-cell integrated response resulting from the activation of hNTS1 with NT, NT (8-13) or NN. Impedance monitoring is a noninvasive label-free 
technique that allows the real-time measurement of dynamic mass redistribution (DMR) in living cells grown on gold-plated electrodes and exposed to different ligands. As shown in Fig. 5 A-F, NT, NT(8-13), and NN produced a similar response profile over time, for each ligand concentration tested (i.e. 1, 10, 100, and $1000 \mathrm{nM}$ ), in which at least two distinct phases and one transient plateau could be observed. Immediately after the stimulation of CHO-hNTS1 cells, a rapid increase in the response signal was observed until it reached a transient maximum value followed by a plateau, which is only present for stimulations at 100 and $1000 \mathrm{nM}$. This maximum was then pursued by a slow decrease of the response until a return to the baseline at $180 \mathrm{~min}$ after stimulation. NT induced a more sustained response than NT(8-13) and NN at high concentrations (100 and $1000 \mathrm{nM}$ ) but the global shape of the curve was not affected (Fig. 5 C-D). As a control, L15 media was applied to CHO-hNTS1 cells, which did not produce any variations in the normalized response aside from the injection peak (Fig. 5E). As expected, the response of CHOhNTS1 cells stimulated with $10 \mu \mathrm{M}$ of the NTS1 receptor antagonist SR48692 did not show any changes in the normalized response (Fig. 5G). A whole-cell integrated concentration-response curve was generated using the maximum value of the normalized response for each ligand and is shown in Fig. 5G. The cellular response induced by either NT, NT(8-13) or NN was comparable, even at non-saturating ligand concentrations and no significant differences were observed between the $\mathrm{EC}_{50}$ values of the whole-cell integrated response triggered by these three ligands (Table 2). To corroborate the results obtained using the impedance-based cell response, we next used cellbased surface plasmon resonance (SPR) to monitor the whole-cell integrated response resulting from the activation of hNTS1 with $1 \mu \mathrm{MNT}$, NT (8-13) or NN. Like the impedance-based method, SPR is a noninvasive label-free technique that allows to quantify DMR in living cells grown on SPR substrate; however, this technique is based on an optical measurement instead of an electrical 
measurement. As shown in Fig. 6 A-F, NT, NT(8-13), and NN produced an SPR response profile in which at least three distinct phases and two transient plateaus could be observed. As a control, NT was applied to CHO-K1 cells (Mock cells) (Fig. 6A) or L15 media was applied to CHOhNTS1 cells (Fig. 6B), which did not produce any variations in the SPR signal aside from the injection peak. Prior to stimulation, the SPR signal was stable, indicating a steady-state level of cellular activity. Immediately after the stimulation of CHO-hNTS1 cells, a rapid decline in the SPR signal was observed until it reached a transient minimum value $(-6.8 \pm 1.0$ reflectance variation unit (RVU), $-4.2 \pm 1.0 \mathrm{RVU}$ and $-5.0 \pm 1.2 \mathrm{RVU}$ for $\mathrm{NT}, \mathrm{NT}(8-13)$ and $\mathrm{NN}$, respectively), which was identified as phase I. We next observed an increase in the SPR signal (phase II), which could be quantified by calculating the difference between the minimum and the first observed plateau when cell response progressed toward a transient stable state after stimulation ( $22.0 \pm 1.2$ RVU for NT, $20.2 \pm 2.1 \mathrm{RVU}$ for NT(8-13) and $21.0 \pm 0.8 \mathrm{RVU}$ for NN). Following this first plateau, another increase was observed and was identified as phase III. This third phase was quantified by calculating the difference between the value at the first plateau and the value at the second plateau after stimulation $(13.7 \pm 2.8 \mathrm{RVU}, 11.7 \pm 3.1 \mathrm{RVU}$ and $13.8 \pm 1.3 \mathrm{RVU}$ for NT, $\mathrm{NT}(8-13)$ and NN, respectively). No significant differences were observed between all phases of the SPR response (Fig. 6F).

DMR quantification experiments (changes in cell monolayer impedance and SPR) thus revealed similar cellular behaviors in response to NT, NT(8-13) or NN stimulation, suggesting that the integrated signatures triggered by NTS1 activation lead to similar cellular responses. 


\section{Discussion}

In the present study, we report the signaling signature of the hNTS1 receptor in CHO-K1 cells following its activation by NT, NN, and NT(8-13) using BRET-based and label-free whole-cell DMR sensing assays (changes in cell monolayer impedance and SPR). The characterization of the hNTS1-mediated cellular signaling network revealed that NT, NT(8-13), and NN activate the G $\alpha_{\mathrm{q}^{-}}$ , $\mathrm{G} \alpha_{\mathrm{i} / \mathrm{o}^{-}}, \mathrm{G} \alpha_{13^{-}}$, and $\mathrm{G} \alpha_{\mathrm{s}}$-protein signaling pathways with similar efficacies and potencies. Furthermore, all ligands stimulated the production of inositol phosphate, modulated cAMP accumulation as well as activated ERK1/2 in our cellular model (See Fig. 7 for a comprehensive scheme of the signaling pathways activated by hNTS1). Nevertheless, we noticed that NN was less potent than NT and NT(8-13) for inducing the recruitment of $\beta$-arrestins, whereas NT(8-13) was more potent than NT and NN in activating the IP signaling pathway. Despite these distinct signaling profiles toward different effector systems, the integrated signatures revealed by two different label-free whole-cell DMR sensing assays (i.e. changes in cell monolayer impedance and SPR; Fig. 5 and Fig. 6) led to identical cellular responses by the three ligands.

Interaction between hNTS1 and G proteins have been mainly based on the activation of second messenger signaling pathways and not on a direct assessment of the physical interactions between the receptor and the heterotrimeric G proteins. Our results reveal that hNTS1 stimulation promoted the engagement of different $G$ protein families at the $G$ protein level, which was previously demonstrated by their coupling to various downstream signaling pathways and by the use of signal transduction inhibitors (Pelaprat, 2006; Vincent et al., 1999; Z. Wu et al., 2012). We found that hNTS1 stimulation induced $\mathrm{G} \alpha_{\mathrm{q}}$ activation and the subsequent production of inositol phosphate. The $\mathrm{G} \alpha_{\mathrm{q}}$-dependent pathway was confirmed by the application of the $\mathrm{G} \alpha_{\mathrm{q}}$ inhibitor UBOQIC. 
These results are consistent with the previous findings in other cell types, which show that NTS1, via its coupling to the $\mathrm{G} \alpha_{\mathrm{q}}$ subunit, mediates the activation of phospholipase $\mathrm{C}$ and the production of IP and diacylglycerol, leading to the mobilization of intracellular calcium and activation of PKC in both neuronal and non-neuronal cell types (Amar et al., 1987; Choi et al., 1999; Najimi et al., 2002; Oury-Donat et al., 1995; Schaeffer et al., 1995; Skrzydelski et al., 2003; Snider et al., 1986; Wang and $\mathrm{T} . \mathrm{Wu}, 1996)$.

NTS1-induced $\mathrm{G} \alpha_{\mathrm{i}_{\mathrm{o}}}$ activation was previously suggested by experimental studies that showed the PTX-dependent sensitivity of $\left[{ }^{35} \mathrm{~S}\right]-\mathrm{GTP} \gamma \mathrm{S}$ binding following NT activation (Gailly et al., 2000) and by inhibiting cAMP production in N1E115 cells (Bozou et al., 1986; Oury-Donat et al., 1995). Reports have also shown that NT stimulated cAMP production in heterologous cells expressing human or rat NTS1 as well as in pancreatic cancer cells endogenously expressing hNTS1, indicating that NTS1 also couples to $\mathrm{G}_{\mathrm{s}}$ (Ishizuka et al., 1993; Richard et al., 2001; Sarret et al., 2010; Skrzydelski et al., 2003; Yamada et al., 1993). Here, our results provide a new insight into the discrepancy that demonstrated both $\mathrm{G \alpha}_{\mathrm{i} / 0^{-}}$and $\mathrm{G}_{\mathrm{s}} \mathrm{-NTS} 1$ coupling (Fig. 2). Indeed, we demonstrate that NT-induced cAMP production was increased in the presence of PTX. Since G $\alpha_{\mathrm{s}}$ and $\mathrm{G}_{\mathrm{i} / \mathrm{o}}$ regulate the same intracellular effector, these results suggest that in this host cell system, hNTS1 is preferentially coupled to adenylyl cyclase through $\mathrm{G} \alpha_{\mathrm{s}}$ rather than $\mathrm{G} \alpha_{\mathrm{i} /}$, consequently leading to cAMP production. It has also been suggested that NTS1 causes an increase in the cellular level of cAMP through the $\mathrm{G} \alpha_{\mathrm{q} / 11}$-mediated activation of calcium-dependent adenylyl cyclase in PC3 cancer cells (Carraway and Mitra, 1998). Here, we found that the $\mathrm{G} \alpha_{\mathrm{q}}$ blocker UBOQIC did not affect NT-induced cAMP accumulation. These data thus reinforce the central role played by $\mathrm{G} \alpha_{\mathrm{s}}$ in cAMP production. 
We also demonstrate the ability of NTS1 to engage $\mathrm{G}_{13}$ (Fig. 1). This finding is in line with reports showing that NT modulates the activity of small Rho GTPases, such as Cdc42 and Rac1, downstream of $\mathrm{G \alpha}_{13}$ in U373 glioblastoma cells (Servotte et al., 2006). These results further suggest that NTS1 activation could mediate cytoskeletal rearrangements and lead to the emergence of stress fibers and cell migration (Moura et al., 2013).

$\beta$-Arrestins bind agonist-activated receptors and play a central role in mediating GPCR desensitization and internalization (Ferguson, 2001; Pierce and Lefkowitz, 2001). We therefore investigated the effects of hNTS1 stimulation on G protein-independent signaling by monitoring the recruitment $\beta$-arrestins 1 and 2 to the receptor (Fig. 3). Our results of hNTS1-triggered $\beta$ arrestin recruitment indicate rapid binding of both $\beta$-arrestins to the receptor when subnanomolar levels of ligands are used. The cellular trafficking of $\beta$-arrestins is differentially regulated via their association to distinct GPCR subtypes; class A receptors interact with $\beta$-arrestin 2 with higher affinities than $\beta$-arrestin 1 , while class $B$ receptors bind both $\beta$-arrestins with similarly high affinities (Drake et al., 2006). This type of $\beta$-arrestin-receptor interaction appears to determine receptor fate; GPCRs that are tightly bound to $\beta$-arrestins (class B) are more frequently targeted to lysosomal compartments where they undergo proteolytic degradation, whereas receptors dissociating rapidly from $\beta$-arrestins (class A) are recycled back to the plasma membrane (Drake et al., 2006). Our results support the classification of hNTS1 as a class B GPCR (Oakley et al., 2001; 2000; Zhang, 1999) and are consistent with previous observations demonstrating that hNTS1 receptors are trafficked to lysosomal compartments for degradation (Vandenbulcke et al., 2000). Our results also reveal that both NT and NT(8-13) were more potent in inducing the recruitment of $\beta$-arrestins compared to NN. These differences might be driven by the presence of GRK kinases, which have been shown to influence GPCR signaling and trafficking (Liggett, 2011). Accordingly, 
Inagaki et al. (2015) recently reported that GRK2 and GRK5 differentially phosphorylate the NTS1 receptor. Phosphorylation of NTS1 by GRK2 is agonist-independent and occurs only on the C-terminal Ser residues, whereas phosphorylation of NTS1 by GRK5 is agonist-dependent and requires the phosphorylation of the Ser and Thr residues located in intracellular loop 3 and the Cterminus. Since these GPCR kinases seem to be endogenously expressed in CHO-K1 cells (OsorioEspinoza et al., 2014), we can therefore speculate that they could affect the responses induced by the different NT agonists and lead to different profiles of $\beta$-arrestin recruitment.

NTS1 was found to be overexpressed in several cancer cell lines (Mustain et al., 2011), such as colonic adenocarcinomas (Evers, 2006; Müller et al., 2011; Yoshinaga et al., 1992; Zhao et al., 2007), breast (Dupouy et al., 2009; Souazé et al., 2006), and lung cancers (Allen et al., 1988; Bunn et al., 1992; Davis et al., 1991). Thus, we were also interested in investigating whether NTS1 signaling by NT, NT(8-13), and NN led to activation of the MAPK proliferative pathway. Since many signaling pathways, including G protein-dependent and G protein-independent pathways, lead to ERK1/2 phosphorylation, the pharmacological inhibitors of upstream signaling molecules were used to decipher the contribution of the various effectors involved (Fig. 4). In contrast to previous studies demonstrating that the EGFR inhibitor gefitinib inhibited NT-induced ERK1/2 phosphorylation in colonic HT-29 and prostatic PC3 cancer cell lines (Hassan et al., 2004; Müller et al., 2011), we did not observe that EGFR transactivation was required for ERK1/2 activation. These discrepancies may be related to the fact that the cancer cell lines express the third member of the NT receptor family NTS3 (Morinville et al., 2004; Sarret et al., 2001). Indeed, as observed by (Martin et al., 2002), co-expression of NTS3 with NTS1 significantly affects NT-dependent intracellular signaling, such as ERK1/2 phosphorylation. Our results also reveal that ERK1/2 activation does not involve $\mathrm{G} \alpha_{13}$ recruitment since the highly selective ROCK inhibitor Y27632 
did not induce any changes in ERK1/2 phosphorylation. Several lines of evidence suggest that in addition to their role in desensitization/internalization, $\beta$-arrestins act as signal transduction scaffolds for ERK1/2 activation following agonist-stimulated receptor internalization (Pierce and Lefkowitz, 2001). Since hNTS1 internalizes via clathrin-coated pits and through a dynamindependent mechanism (Savdie et al., 2006; Vandenbulcke et al., 2000; Vincent et al., 1998), we further examined if dynasore that interferes with the GTPase activity of dynamin and blocks receptor endocytosis exerted an inhibitory action on ERK1/2 activation. No significant changes in NT-induced ERK1/2 phosphorylation were observed in the presence of dynasore, thus suggesting that hNTS1-mediated ERK1/2 activation occurs independent of hNTS1 internalization and of $\beta$ arrestin signaling in this cell type.

Depending on the receptor and cell type, ERK1/2 activation may be mediated by PTX-sensitive or PTX-insensitive G proteins. We demonstrate here that $\mathrm{G} \alpha_{\mathrm{q}}$ inactivation by the UBOQIC blocker or inhibition of the downstream PKC by Gö6983 partially blocked ERK1/2 phosphorylation. These results thus support the involvement of the PTX-insensitive $G \alpha_{\mathrm{q}}$-PLC $\beta$-DAG-PKC pathway in hNTS1-induced ERK1/2 activation. This finding is in agreement with previous findings showing that NT stimulates ERK1/2 phosphorylation through a PKC-Raf-1-dependent signaling pathway (Guha et al., 2003). Our results also reveal the key role played by $\mathrm{G}_{\mathrm{i} / \mathrm{o}}$ in hNTS1-mediated ERK1/2 phosphorylation. Indeed, locking $\mathrm{G}_{\mathrm{i} / \mathrm{o}}$ in its inactive conformation by PTX pretreatment led to a complete loss of ERK1/2 phosphorylation. This PTX-sensitive effect of ERK1/2 activation is $G \alpha_{\mathrm{i} / \mathrm{o}}$ dependent since the $\mathrm{G} \beta / \gamma$ inhibitor gallein does not affect the ERK1/2 phosphorylation induced by NT. These data are consistent with other studies reporting that NT stimulates the transcription of the immediate-early gene Krox-24, a target of the ERK1/2 pathway, through a PTX-sensitive pathway (Poinot-Chazel et al., 1996). 
The most unexpected result found here is that $\mathrm{G}_{\mathrm{i} / \mathrm{o}}$ inhibition by PTX completely prevents $\mathrm{hNTS} 1$ induced ERK1/2 phosphorylation (Fig. 4). This finding is indeed surprising since we have demonstrated that ERK1/2 activation is also regulated in a $\mathrm{G} \alpha_{\mathrm{q}}$-PLC $\beta$-DAG-PKC-dependent manner. This result may be explained by the fact that PTX, which blocks the $\mathrm{G} \alpha_{\mathrm{i} / \mathrm{o}}$-mediated inhibition of adenylyl cyclase thereby promoting cAMP production, would inhibit the activation of Raf-1 (Piiper et al., 2000). Raf-1 inhibition would reduce the hNTS1-induced ERK phosphorylation through the PTX-insensitive G $\alpha_{q}$-PLC $\beta$-DAG-PKC pathway (Fig. 7). This hypothesis is supported by our demonstration that inactivation of $\mathrm{G \alpha}_{\mathrm{i} / \mathrm{o}}$ by PTX increases the intracellular cAMP level in CHO-hNTS1 cells in response to NT (Fig. 2). Furthermore, the absence of complete inhibition of ERK1/2 activation using the c-Src inhibitor PD166285 further reinforces the involvement of the PTX-insensitive G $\alpha_{q}$-PLC $\beta$-DAG-PKC-Raf-1-dependent pathway in ERK1/2 activation. We can thus conclude that the full activation of ERK1/2 in CHOhNTS1 cells by NT requires signaling through both a PTX-sensitive $\mathrm{G} \alpha_{\mathrm{i} / 0^{-}} \mathrm{c}-\mathrm{Src}$ signaling pathway and a PLC $\beta$-DAG-PKC-Raf-1-dependent pathway downstream of $\mathrm{G \alpha}_{q}$ (Fig. 7).

Altogether, our results demonstrate the functional coupling of agonist-stimulated hNTS1 to the G proteins $\mathrm{G} \alpha_{\mathrm{q}}, \mathrm{G} \alpha_{\mathrm{il}}, \mathrm{G} \alpha_{\mathrm{oA}}$, and $\mathrm{G} \alpha_{13}$ as well as its ability to recruit $\beta$-arrestins and activate the IP1, cAMP, and ERK1/2 second messenger signaling cascades. The BRET-based and label-free wholecell sensing tools used here to decipher the NTS1 signaling signature may also be helpful in accelerating the validation of potential NTS1 biased ligands. Biased signaling of GPCRs is of growing interest to drug discovery, particularly in the quest to identify compounds with high therapeutic potential while reducing unwanted side effects (Correll and McKittrick, 2014; Garland, 2013; Kenakin, 2012). Our study will form the basis for the future development of therapeutics targeting hNTS1 in clinical indications such as pain management. 
This is the accepted (postprint) version of the following article: Besserer-Offroy É, et al. (2017). Eur J Pharmacol. doi: 10.1016/j.ejphar.2017.03.046, which has been accepted and published in its final form at http://www.sciencedirect.com/science/article/pii/S0014299917302157

(c) 2017. This manuscript version is made available under the http://creativecommons.org/licenses/by-nc-nd/4.0/ 


\section{Acknowledgments}

We gratefully acknowledge the Canadian Institute of Health Research (CIHR), National Science and Engineering Research Council of Canada (NSERC), and the FRQ-S funded Réseau Québécois de Recherche sur le Médicament (RQRM) for their financial support. EBO was supported by a research fellowship from the Institut de Pharmacologie de Sherbrooke (IPS) and Centre d'Excellence en Neurosciences de l'Université de Sherbrooke (CNS). PS holds a Canada Research Chair in Neurophysiopharmacology of Chronic Pain. Drs M. Bouvier, T. Hebert, S.A. Laporte, G. Pineyro, J.-C. Tardif and E. Thorin (CQDM Team) are also acknowledged for providing us with the biosensors. The authors declare no conflicts of interest. 


\section{References}

Allen, A.E., Carney, D.N., Moody, T.W., 1988. Neurotensin binds with high affinity to small cell lung cancer cells. Peptides 9 Suppl 1, 57-61.

Amar, S., Kitabgi, P., Vincent, J.-P., 1987. Stimulation of inositol phosphate production by neurotensin in neuroblastoma N1E115 cells: implication of GTP-binding proteins and relationship with the cyclic GMP response. J Neurochem 49, 999-1006.

Azriel, Y., Burcher, E., 2001. Characterization and autoradiographic localization of neurotensin binding sites in human sigmoid colon. J. Pharmacol. Exp. Ther. 297, 1074-1081.

Bockaert, J., 1999. Molecular tinkering of G protein-coupled receptors: an evolutionary success. The EMBO Journal 18, 1723-1729. doi:10.1093/emboj/18.7.1723

Bonacci, T.M., Mathews, J.L., Yuan, C., Lehmann, D.M., Malik, S., Wu, D., Font, J.L., Bidlack, J.M., Smrcka, A.V., 2006. Differential targeting of Gbetagamma-subunit signaling with small molecules. Science 312, 443-446. doi:10.1126/science.1120378

Bozou, J.C., Kitabgi, P., Amar, S., Vincent, J.-P., 1986. Neurotensin-mediated inhibition of cyclic AMP formation in neuroblastoma N1E115 cells: involvement of the inhibitory GTP-binding component of adenylate cyclase. Molecular Pharmacology 29, 489-496.

Breton, B., Sauvageau, É., Zhou, J., Bonin, H., Le Gouill, C., Bouvier, M., 2010. Multiplexing of multicolor bioluminescence resonance energy transfer. Biophys. J. 99, 4037-4046. doi:10.1016/j.bpj.2010.10.025

Bunn, P.A., Dienhart, D.G., Chan, D., Tagawa, M., Jewett, P., 1992. Effects of neuropeptides on human lung and breast cancer cells. J. Natl. Cancer Inst. Monographs 145-151.

Carraway, R.E., Mitra, S.P., 1998. Neurotensin enhances agonist-induced cAMP accumulation in PC3 cells via Ca2+ -dependent adenylyl cyclase(s). Molecular and Cellular Endocrinology 
$144,47-57$.

Carraway, R.E., Mitra, S.P., 1994. Binding and biologic activity of neurotensin in guinea pig ileum. Peptides 15, 1451-1459.

Chabot, V., Cuerrier, C.M., Escher, E., Aimez, V., Grandbois, M., Charette, P.G., 2009.

Biosensing based on surface plasmon resonance and living cells. Biosens Bioelectron 24, 1667-1673. doi:10.1016/j.bios.2008.08.025

Chalon, P., Vita, N., Kaghad, M., Guillemot, M., Bonnin, J., Delpech, B., Le Fur, G., Ferrara, P., Caput, D., 1996. Molecular cloning of a levocabastine-sensitive neurotensin binding site. FEBS Lett. 386, 91-94.

Choi, S.Y., Chae, H.D., Park, T.J., Ha, H., Kim, K.T., 1999. Characterization of high affinity neurotensin receptor NTR1 in HL-60 cells and its down regulation during granulocytic differentiation. Br. J. Pharmacol. 126, 1050-1056. doi:10.1038/sj.bjp.0702378

Claing, A., Laporte, S., Caron, M.G., Lefkowitz, R.J., 2002. Endocytosis of G protein-coupled receptors: roles of $\mathrm{G}$ protein-coupled receptor kinases and beta-arrestin proteins. Prog. Neurobiol. 66, 61-79.

Coppola, T., Béraud-Dufour, S., Antoine, A., Vincent, J.-P., Mazella, J., 2008. Neurotensin protects pancreatic beta cells from apoptosis. Int. J. Biochem. Cell Biol. 40, 2296-2302. doi:10.1016/j.biocel.2008.03.015

Correll, C.C., McKittrick, B.A., 2014. Biased Ligand Modulation of Seven Transmembrane Receptors (7TMRs): Functional Implications for Drug Discovery. J. Med. Chem. doi:10.1021/jm401677g

Cuerrier, C.M., Chabot, V., Vigneux, S., Aimez, V., Escher, E., Gobeil, F., Charette, P.G., Grandbois, M., 2008. Surface Plasmon Resonance Monitoring of Cell Monolayer Integrity: 
Implication of Signaling Pathways Involved in Actin-Driven Morphological Remodeling. Cell Mol Bioeng 1, 229-239. doi:10.1007/s12195-008-0028-4

Davis, T.P., Crowell, S., McInturff, B., Louis, R., Gillespie, T., 1991. Neurotensin may function as a regulatory peptide in small cell lung cancer. Peptides 12, 17-23.

Demeule, M., Beaudet, N., Régina, A., Besserer-Offroy, É., Murza, A., Tétreault, P., Belleville, K., Ché, C., Larocque, A., Thiot, C., Béliveau, R., Longpré, J.-M., Marsault, É., Leduc, R., Lachowicz, J.E., Gonias, S.L., Castaigne, J.-P., Sarret, P., 2014. Conjugation of a brainpenetrant peptide with neurotensin provides antinociceptive properties. J. Clin. Invest. 124, 1199-1213. doi:10.1172/JCI70647

Drake, M.T., Lefkowitz, R.J., Shenoy, S.K., 2006. Trafficking of G protein-coupled receptors. Circulation Research 99, 570-582. doi:10.1161/01.RES.0000242563.47507.ce

Dupouy, S., Viardot-Foucault, V., Alifano, M., Souazé, F., Plu-Bureau, G., Chaouat, M., Lavaur, A., Hugol, D., Gespach, C., Gompel, A., Forgez, P., 2009. The neurotensin receptor-1 pathway contributes to human ductal breast cancer progression. PLoS ONE 4, e4223. doi:10.1371/journal.pone.0004223

Ehrhardt, C., Schmolke, M., Matzke, A., Knoblauch, A., Will, C., Wixler, V., Ludwig, S., 2006. Polyethylenimine, a cost-effective transfection reagent. Signal Transduction 6, 179-184. doi:10.1002/sita.200500073

Evers, B.M., 2006. Neurotensin and growth of normal and neoplastic tissues. Peptides 27, 2424 2433. doi:10.1016/j.peptides.2006.01.028

Feifel, D., Goldenberg, J., Melendez, G., Shilling, P.D., 2010. The acute and subchronic effects of a brain-penetrating, neurotensin-1 receptor agonist on feeding, body weight and temperature. Neuropharmacology 58, 195-198. doi:10.1016/j.neuropharm.2009.07.001 
Feng, Y.-P., Wang, J., Dong, Y.-L., Wang, Y.-Y., Li, Y.-Q., 2015. The roles of neurotensin and its analogues in pain. Curr. Pharm. Des. 21, 840-848.

Ferguson, S.S., Downey, W.E., Colapietro, A.M., Barak, L.S., Ménard, L., Caron, M.G., 1996. Role of beta-arrestin in mediating agonist-promoted $\mathrm{G}$ protein-coupled receptor internalization. Science 271, 363-366. doi:10.1126/science.271.5247.363

Ferguson, S.S.G., 2001. Evolving concepts in G protein-coupled receptor endocytosis: the role in receptor desensitization and signaling. Pharmacological Reviews 53, 1-24.

Gailly, P., Najimi, M., Hermans, E., 2000. Evidence for the dual coupling of the rat neurotensin receptor with pertussis toxin-sensitive and insensitive G-proteins. FEBS Lett. 483, 109-113.

Galés, C., Van Durm, J.J.J., Schaak, S., Pontier, S., Percherancier, Y., Audet, M., Paris, H., Bouvier, M., 2006. Probing the activation-promoted structural rearrangements in preassembled receptor-G protein complexes. Nat. Struct. Mol. Biol. 13, 778-786. doi:10.1038/nsmb1134

Garland, S.L., 2013. Are GPCRs still a source of new targets? Journal of Biomolecular Screening 18, 947-966. doi:10.1177/1087057113498418

Grisshammer, R., Hermans, E., 2001. Functional coupling with Galpha(q) and Galpha(i1) protein subunits promotes high-affinity agonist binding to the neurotensin receptor NTS-1 expressed in Escherichia coli. FEBS Lett. 493, 101-105.

Guha, S., Lunn, J.A., Santiskulvong, C., Rozengurt, E., 2003. Neurotensin stimulates protein kinase C-dependent mitogenic signaling in human pancreatic carcinoma cell line PANC-1. Cancer Res. 63, 2379-2387.

Hassan, S., Dobner, P.R., Carraway, R.E., 2004. Involvement of MAP-kinase, PI3-kinase and EGF-receptor in the stimulatory effect of Neurotensin on DNA synthesis in PC3 cells. Regul. 
Pept. 120, 155-166. doi:10.1016/j.regpep.2004.03.004

Inagaki, S., Ghirlando, R., Vishnivetskiy, S.A., Homan, K.T., White, J.F., Tesmer, J.J.G., Gurevich, V.V., Grisshammer, R., 2015. G Protein-Coupled Receptor Kinase 2 (GRK2) and 5 (GRK5) Exhibit Selective Phosphorylation of the Neurotensin Receptor in Vitro. Biochemistry 54, 4320-4329. doi:10.1021/acs.biochem.5b00285

Inamdar, V., Patel, A., Manne, B.K., Dangelmaier, C., Kunapuli, S.P., 2015. Characterization of UBO-QIC as a Gaq inhibitor in platelets. Platelets 26, 1-8. doi:10.3109/09537104.2014.998993

Ishizuka, J., Townsend, C.M., Thompson, J.C., 1993. Neurotensin regulates growth of human pancreatic cancer. Ann. Surg. 217, 439-45- discussion 446.

Kenakin, T.P., 2013. New concepts in pharmacological efficacy at 7TM receptors: IUPHAR review 2. Br. J. Pharmacol. 168, 554-575. doi:10.1111/j.1476-5381.2012.02223.x

Kenakin, T.P., 2012. The potential for selective pharmacological therapies through biased receptor signaling. BMC Pharmacol Toxicol 13, 3. doi:10.1186/2050-6511-13-3

Kitabgi, P., Amar, S., Vincent, J.-P., 1986. Activation of phosphatidylinositol turnover by neurotensin receptors in the human colonic adenocarcinoma cell line HT29. FEBS Lett. 201, $31-36$.

Koole, C., Wootten, D., Simms, J., Valant, C., Sridhar, R., Woodman, O.L., Miller, L.J., Summers, R.J., Christopoulos, A., Sexton, P.M., 2010. Allosteric ligands of the glucagon-like peptide 1 receptor (GLP-1R) differentially modulate endogenous and exogenous peptide responses in a pathway-selective manner: implications for drug screening. Molecular Pharmacology 78, 456-465. doi:10.1124/mol.110.065664

Liggett, S.B., 2011. Phosphorylation barcoding as a mechanism of directing GPCR signaling. 
Science Signaling 4, pe36. doi:10.1126/scisignal.2002331

Luttrell, D.K., Luttrell, L.M., 2004. Not so strange bedfellows: G-protein-coupled receptors and Src family kinases. Oncogene 23, 7969-7978. doi:10.1038/sj.onc.1208162

Mangmool, S., Kurose, H., 2011. G(i/o) protein-dependent and -independent actions of Pertussis Toxin (PTX). Toxins (Basel) 3, 884-899. doi:10.3390/toxins3070884

Marinissen, M.J., Gutkind, J.S., 2001. G-protein-coupled receptors and signaling networks: emerging paradigms. Trends in Pharmacological Sciences 22, 368-376.

Martin, S., Navarro, V., Vincent, J.-P., Mazella, J., 2002. Neurotensin receptor-1 and -3 complex modulates the cellular signaling of neurotensin in the HT29 cell line. Gastroenterology 123, $1135-1143$.

Mazella, J., Botto, J.M., Guillemare, E., Coppola, T., Sarret, P., Vincent, J.-P., 1996. Structure, functional expression, and cerebral localization of the levocabastine-sensitive neurotensin/neuromedin N receptor from mouse brain. J. Neurosci. 16, 5613-5620.

Mazella, J., Vincent, J.-P., 2006. Functional roles of the NTS2 and NTS3 receptors. Peptides.

Mazella, J., Zsürger, N., Navarro, V., Chabry, J., Kaghad, M., Caput, D., Ferrara, P., Vita, N., Gully, D., Maffrand, J.P., Vincent, J.-P., 1998. The 100-kDa neurotensin receptor is gp95/sortilin, a non-G-protein-coupled receptor. J. Biol. Chem. 273, 26273-26276.

Morinville, A., Vincent, J.-P., Martin, S., Lavallée, M., Beaudet, A., Mazella, J., 2004. Internalization and trafficking of neurotensin via NTS3 receptors in HT29 cells. Int. J. Biochem. Cell Biol. 36, 2153-2168. doi:10.1016/j.biocel.2004.04.013

Moura, L.I.F., Silva, L., Leal, E.C., Tellechea, A., Cruz, M.T., Carvalho, E., 2013. Neurotensin modulates the migratory and inflammatory response of macrophages under hyperglycemic conditions. Biomed Res Int 2013, 941764-13. doi:10.1155/2013/941764 
Mustain, W.C., Rychahou, P.G., Evers, B.M., 2011. The role of neurotensin in physiologic and pathologic processes. Curr Opin Endocrinol Diabetes Obes 18, 75-82. doi:10.1097/MED.0b013e3283419052

Müller, K.M., Tveteraas, I.H., Aasrum, M., Ødegård, J., Dawood, M., Dajani, O., Christoffersen, T., Sandnes, D.L., 2011. Role of protein kinase C and epidermal growth factor receptor signalling in growth stimulation by neurotensin in colon carcinoma cells. BMC Cancer 11, 421. doi:10.1186/1471-2407-11-421

Najimi, M., Gailly, P., Maloteaux, J.M., Hermans, E., 2002. Distinct regions of C-terminus of the high affinity neurotensin receptor mediate the functional coupling with pertussis toxin sensitive and insensitive G-proteins. FEBS Lett. 512, 329-333.

Narumiya, S., Ishizaki, T., Ufhata, M., 2000. Use and properties of ROCK-specific inhibitor Y27632, in: Regulators and Effectors of Small GTPases - Part D: Rho Family, Methods in Enzymology. Elsevier, pp. 273-284. doi:10.1016/S0076-6879(00)25449-9

New, D.C., Wong, Y.H., 2007. Molecular mechanisms mediating the G protein-coupled receptor regulation of cell cycle progression. J Mol Signal 2, 2. doi:10.1186/1750-2187-2-2

Oakley, R.H., Laporte, S., Holt, J.A., Barak, L.S., Caron, M.G., 2001. Molecular determinants underlying the formation of stable intracellular $G$ protein-coupled receptor-beta-arrestin complexes after receptor endocytosis*. J. Biol. Chem. 276, 19452-19460. doi:10.1074/jbc.M101450200

Oakley, R.H., Laporte, S.A., Holt, J.A., Caron, M.G., Barak, L.S., 2000. Differential affinities of visual arrestin, beta arrestin1, and beta arrestin 2 for $\mathrm{G}$ protein-coupled receptors delineate two major classes of receptors. J. Biol. Chem. 275, 17201-17210. doi:10.1074/jbc.M910348199

Offermanns, S., 2003. G-proteins as transducers in transmembrane signalling. Progress in 
Biophysics and Molecular Biology 83, 101-130. doi:10.1016/S0079-6107(03)00052-X

Osadchii, O.E., 2015. Emerging role of neurotensin in regulation of the cardiovascular system.

Eur. J. Pharmacol. doi:10.1016/j.ejphar.2015.05.025

Osorio-Espinoza, A., Escamilla-Sánchez, J., Aquino-Jarquin, G., Arias-Montaño, J.-A., 2014.

Homologous desensitization of human histamine $\mathrm{H}_{3}$ receptors expressed in CHO-K1 cells.

Neuropharmacology 77, 387-397. doi:10.1016/j.neuropharm.2013.09.011

Oury-Donat, F., Thurneyssen, O., Gonalons, N., Forgez, P., Gully, D., Le Fur, G., Soubrie, P., 1995. Characterization of the effect of SR48692 on inositol monophosphate, cyclic GMP and cyclic AMP responses linked to neurotensin receptor activation in neuronal and non-neuronal cells. Br. J. Pharmacol. 116, 1899-1905.

Overland, A.C., Insel, P.A., 2015. Heterotrimeric G proteins directly regulate MMP14/membrane type-1 matrix metalloprotease: a novel mechanism for GPCR-EGFR transactivation. Journal of Biological Chemistry 290, 9941-9947. doi:10.1074/jbc.C115.647073

Panek, R.L., Lu, G.H., Klutchko, S.R., Batley, B.L., Dahring, T.K., Hamby, J.M., Hallak, H., Doherty, A.M., Keiser, J.A., 1997. In vitro pharmacological characterization of PD 166285, a new nanomolar potent and broadly active protein tyrosine kinase inhibitor. J. Pharmacol. Exp. Ther. 283, 1433-1444.

Pelaprat, D., 2006. Interactions between neurotensin receptors and G proteins. Peptides 27, 24762487. doi:10.1016/j.peptides.2006.04.027

Pierce, K.L., Lefkowitz, R.J., 2001. Classical and new roles of beta-arrestins in the regulation of G-protein-coupled receptors. Nat. Rev. Neurosci. 2, 727-733. doi:10.1038/35094577

Piiper, A., Gebhardt, R., Kronenberger, B., Giannini, C.D., Elez, R., Zeuzem, S., 2000. Pertussis toxin inhibits cholecystokinin- and epidermal growth factor-induced mitogen-activated 
protein kinase activation by disinhibition of the cAMP signaling pathway and inhibition of cRaf-1. Molecular Pharmacology 58, 608-613.

Piiper, A., Zeuzem, S., 2004. Receptor tyrosine kinases are signaling intermediates of G proteincoupled receptors. Curr. Pharm. Des. 10, 3539-3545. doi:10.2174/1381612043382936\#sthash.r8iA7cXE.dpuf

Poinot-Chazel, C., Portier, M., Bouaboula, M., Vita, N., Pecceu, F., Gully, D., Monroe, J.G., Maffrand, J.P., Le Fur, G., Casellas, P., 1996. Activation of mitogen-activated protein kinase couples neurotensin receptor stimulation to induction of the primary response gene Krox-24. Biochem. J. 320 ( Pt 1), 145-151.

Premont, R.T., Gainetdinov, R.R., 2007. Physiological roles of G protein-coupled receptor kinases and arrestins. Annu. Rev. Physiol. 69, 511-534. doi:10.1146/annurev.physiol.69.022405.154731

Reiter, E., Lefkowitz, R.J., 2006. GRKs and beta-arrestins: roles in receptor silencing, trafficking and signaling. Trends Endocrinol. Metab. 17, 159-165. doi:10.1016/j.tem.2006.03.008

Richard, F., Kitabgi, P., Barroso, S., Nicolas-Ethève, D., Labbé-Jullié, C., 2001. Impaired G protein coupling of the neurotensin receptor 1 by mutations in extracellular loop 3. Eur. J. Pharmacol. 433, 63-71.

Richard-Lalonde, M., Nagi, K., Audet, N., Sleno, R., Amraei, M., Hogue, M., Balboni, G., Schiller, P.W., Bouvier, M., Hébert, T.E., Pineyro, G., 2013. Conformational dynamics of Kir3.1/Kir3.2 channel activation via $\delta$-opioid receptors. Molecular Pharmacology 83, 416428. doi: $10.1124 / \mathrm{mol} .112 .081950$

Rioux, F., Quirion, R., Kérouac, R., St-Pierre, S., 1982. The pressor effects of neurotensin and related peptides in rats. Neuropeptides. 
Rostène, W.H., Alexander, M.J., 1997. Neurotensin and neuroendocrine regulation. Front Neuroendocrinol 18, 115-173. doi:10.1006/frne.1996.0146

Roussy, G., Sarret, P., Dansereau, M.A., Doré Savard, L., Belleville, K., Beaudet, N., Richelson, E., 2008. Spinal NTS1 receptors regulate nociceptive signaling in a rat formalin tonic pain model. J Neurochem 105, 1100-1114. doi:10.1111/j.1471-4159.2007.05205.x

Rovere, C., Barbero, P., Kitabgi, P., 1996. Evidence that PC2 is the endogenous pro-neurotensin convertase in rMTC 6-23 cells and that PC1- and PC2-transfected PC12 cells differentially process pro-neurotensin. J. Biol. Chem. 271, 11368-11375.

Rozengurt, E., 2007. Mitogenic signaling pathways induced by G protein-coupled receptors. J. Cell. Physiol. 213, 589-602. doi:10.1002/jcp.21246

Sarret, P., Dal Farra, C., Botto, J.M., Navarro, V., Mazella, J., Vincent, J.-P., 2001. Involvement of the neurotensin receptor subtype NTR3 in the growth effect of neurotensin on cancer cell lines. Int. J. Cancer 92, 503-509.

Sarret, P., Hwang, J.R., Baek, M.W., Sim, J., Choi, H.-S., Han, J.M., Kim, Y.L., Hwang, J.-I., Kwon, H.B., Beaudet, N., Seong, J.Y., 2010. Intermolecular cross-talk between NTR1 and NTR2 neurotensin receptor promotes intracellular sequestration and functional inhibition of NTR1 receptors. Biochemical and Biophysical Research Communications 391, 1007-1013. doi:10.1016/j.bbrc.2009.12.007

Savdie, C., Ferguson, S.S.G., Vincent, J.-P., Beaudet, A., Stroh, T., 2006. Cell-type-specific pathways of neurotensin endocytosis. Cell Tissue Res. 324, 69-85. doi:10.1007/s00441-005$0102-3$

Schaeffer, P., Laplace, M.-C., Savi, P., Pflieger, A.-M., GULLY, D., Herbert, J.-M., 1995. Human Umbilical Vein Endothelial Cells Express High Affinity Neurotensin Receptors Coupled to 
Intracellular Calcium Release. J. Biol. Chem. 270, 3409-3413. doi:10.1016/01969781(84)90117-7

Servotte, S., Camby, I., Debeir, O., Deroanne, C., Lambert, C.A., Lapière, C.M., Kiss, R., Nusgens, B., Decaestecker, C., 2006. The in vitro influences of neurotensin on the motility characteristics of human U373 glioblastoma cells. Neuropathology and Applied Neurobiology 32, 575-584. doi:10.1111/j.1365-2990.2006.00760.x

Skrzydelski, D., Rostène, W.H., Lhiaubet, A.-M., Lebeau, A., Forgez, P., Yamada, M., Hermans, E., Pelaprat, D., 2003. Differential involvement of intracellular domains of the rat NTS1 neurotensin receptor in coupling to $G$ proteins: a molecular basis for agonist-directed trafficking of receptor stimulus. Molecular Pharmacology 64, 421-429. doi:10.1124/mol.64.2.421

Smrcka, A.V., 2013. Molecular targeting of $\mathrm{G} \alpha$ and $\mathrm{G} \beta \gamma$ subunits: a potential approach for cancer therapeutics. Trends in Pharmacological Sciences 34, 290-298. doi:10.1016/j.tips.2013.02.006

Snider, R.M., Forray, C., Pfenning, M., Richelson, E., 1986. Neurotensin stimulates inositol phospholipid metabolism and calcium mobilization in murine neuroblastoma clone N1E-115. J Neurochem 47, 1214-1218.

Souazé, F., Dupouy, S., Viardot-Foucault, V., Bruyneel, E., Attoub, S., Gespach, C., Gompel, A., Forgez, P., 2006. Expression of neurotensin and NT1 receptor in human breast cancer: a potential role in tumor progression. Cancer Res. 66, 6243-6249. doi:10.1158/00085472.CAN-06-0450

Souazé, F., Rostène, W.H., Forgez, P., 1997. Neurotensin agonist induces differential regulation of neurotensin receptor mRNA. Identification of distinct transcriptional and post- 
transcriptional mechanisms. J. Biol. Chem. 272, 10087-10094.

St-Pierre, S., Lalonde, J.M., Gendreau, M., Quirion, R., Regoli, D., Rioux, F., 1981. Synthesis of peptides by the solid-phase method. 6. Neurotensin, fragments, and analogues. J. Med. Chem. 24, 370-376. doi:10.1021/jm00136a004

Tanaka, K., Masu, M., Nakanishi, S., 1990. Structure and functional expression of the cloned rat neurotensin receptor. Neuron 4, 847-854.

Toy-Miou-Leong, M., Rostène, W.H., Cortes, C.L., Beaudet, A., Forgez, P., 2004. Receptor trafficking via the perinuclear recycling compartment accompanied by cell division is necessary for permanent neurotensin cell sensitization and leads to chronic mitogen-activated protein kinase activation. J. Biol. Chem. 279, 12636-12646. doi:10.1074/jbc.M303384200

Vandenbulcke, F., Vincent, J.-P., Nouel, D., Mazella, J., Beaudet, A., 2000. Ligand-induced internalization of neurotensin in transfected COS-7 cells: differential intracellular trafficking of ligand and receptor. J. Cell. Sci. 113 ( Pt 17), 2963-2975.

Vincent, J.-P., Botto, J.M., Chabry, J., Sarret, P., Mazella, J., 1998. Stable expression of the mouse levocabastine-sensitive neurotensin receptor in HEK 293 cell line: binding properties, photoaffinity labeling, and internalization mechanism. Biochemical and Biophysical Research Communications 243, 585-590. doi:10.1006/bbrc.1997.8071

Vincent, J.-P., Mazella, J., Kitabgi, P., 1999. Neurotensin and neurotensin receptors. Trends in Pharmacological Sciences 20, 302-309.

Vita, N., Laurent, P., Lefort, S., Chalon, P., Dumont, X., Kaghad, M., Gully, D., Le Fur, G., Ferrara, P., Caput, D., 1993. Cloning and expression of a complementary DNA encoding a high affinity human neurotensin receptor. FEBS Lett. 317, 139-142.

Vita, N., Oury-Donat, F., Chalon, P., Guillemot, M., Kaghad, M., Bachy, A., Thurneyssen, O., 
Garcia, S., Poinot-Chazel, C., Casellas, P., Keane, P., Le Fur, G., Maffrand, J.P., Soubrie, P., Caput, D., Ferrara, P., 1998. Neurotensin is an antagonist of the human neurotensin NT2 receptor expressed in Chinese hamster ovary cells. Eur. J. Pharmacol. 360, 265-272.

Wang, H.-L., Wu, T., 1996. mediates neurotensin excitation of substantia nigra dopaminergic neurons. Molecular Brain Research 36, 29-36. doi:10.1016/0169-328X(95)00235-K

Wu, Z., Martinez-Fong, D., Trédaniel, J., Forgez, P., 2012. Neurotensin and its high affinity receptor 1 as a potential pharmacological target in cancer therapy. Front Endocrinol (Lausanne) 3, 184. doi:10.3389/fendo.2012.00184

Yamada, M., Watson, M.A., Richelson, E., 1993. Neurotensin stimulates cyclic AMP formation in CHO-rNTR-10 cells expressing the cloned rat neurotensin receptor. Eur. J. Pharmacol. 244, 99-101. doi:10.1016/0922-4106(93)90064-G

Yoshinaga, K., Evers, B.M., Izukura, M., Parekh, D., Uchida, T., Townsend, C.M., Thompson, J.C., 1992. Neurotensin stimulates growth of colon cancer. Surg Oncol 1, 127-134.

Zhang, J., 1999. Cellular Trafficking of G Protein-coupled Receptor/beta -Arrestin Endocytic Complexes. Journal of Biological Chemistry 274, 10999-11006. doi:10.1074/jbc.274.16.10999

Zhao, D., Zhan, Y., Zeng, H., Koon, H.W., Moyer, M.P., Pothoulakis, C., 2007. Neurotensin stimulates expression of early growth response gene-1 and EGF receptor through MAP kinase activation in human colonic epithelial cells. Int. J. Cancer 120, 1652-1656. doi:10.1002/ijc.22407 


\section{Figures}

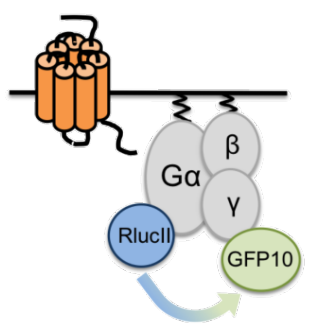

A

$$
\begin{aligned}
& \text { Go } \alpha_{\mathrm{q}} \text {-Rlucll / GFP10-G } \gamma_{1} \\
& \text { hNTS1 }
\end{aligned}
$$

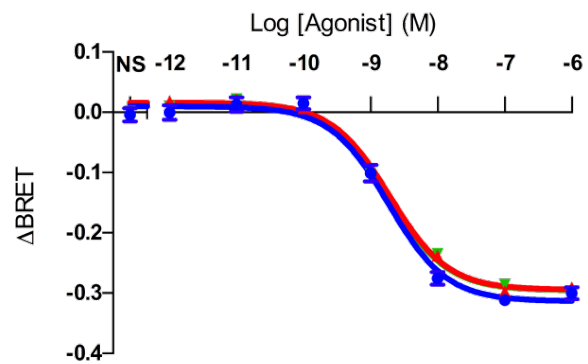

$$
\text { C } \alpha_{\mathrm{oA}}-\text { Rlucll / GFP10-G } \gamma_{1}
$$

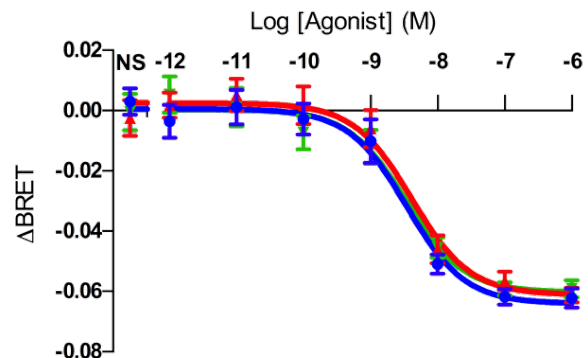

$\rightarrow$ Neurotensin 1-13

$\mp$ Neurotensin 8-13

$\leftarrow$ Neuromedin $\mathrm{N}$
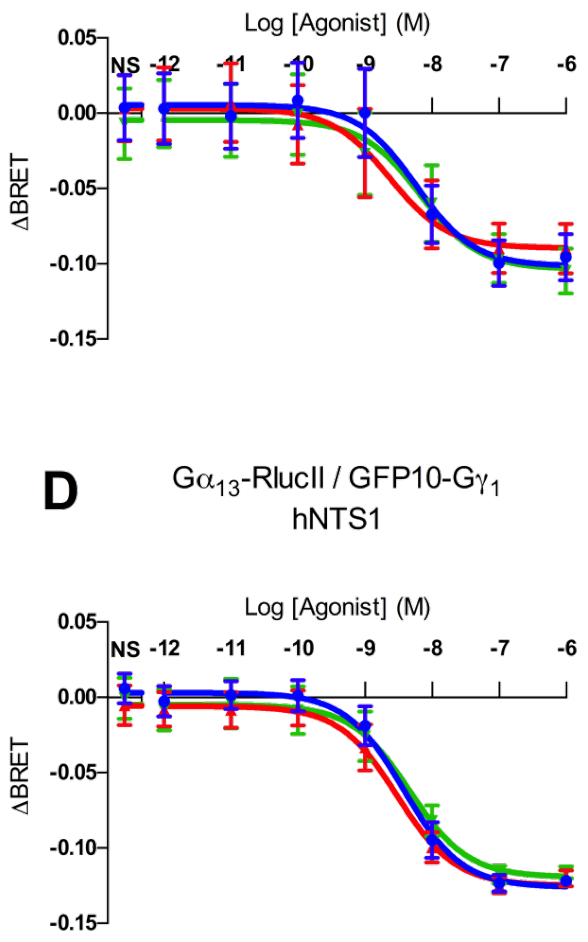

Fig. 1. hNTS1 promotes the engagement of $G$ proteins $G \alpha_{q}, G \alpha_{i 1}, G \alpha_{0 A}$, and $G \alpha_{13}$ in $C H O-$

K1 cells. Effect of increasing concentrations of NT, NT(8-13), or NN on the dissociation of G $\alpha_{\mathrm{q}}$ (A), $\mathrm{G} \alpha_{\mathrm{i} 1}(\mathrm{~B}), \mathrm{G} \alpha_{\mathrm{OA}}(\mathrm{C})$, and $\mathrm{G} \alpha_{13}$ (D). BRET was measured 10 min after the addition of the ligands. Each data set represents the mean of three independent experiments, which were each done in triplicate, and is expressed as the mean \pm S.E.M.. 
A

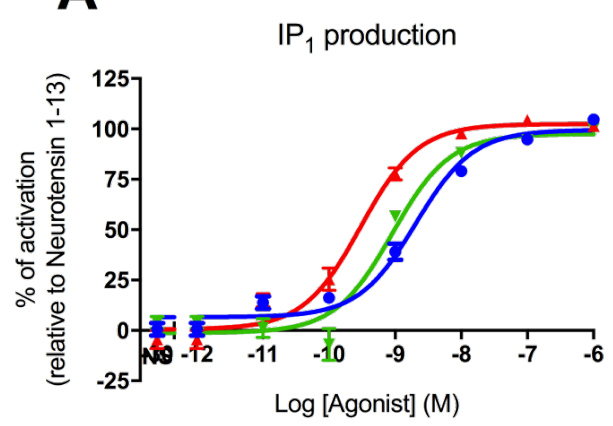

$\mathrm{IP}_{1}$ production



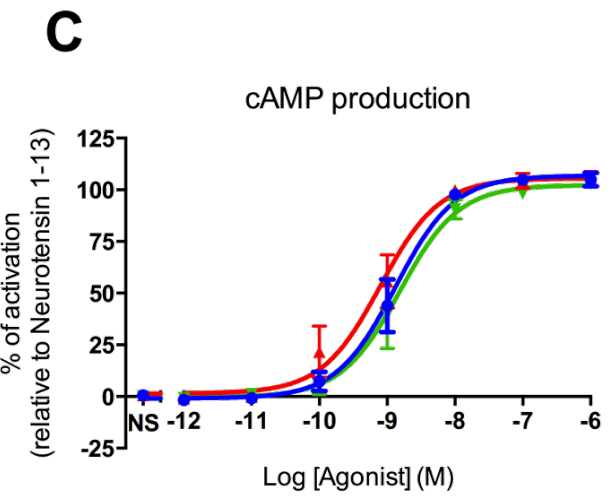

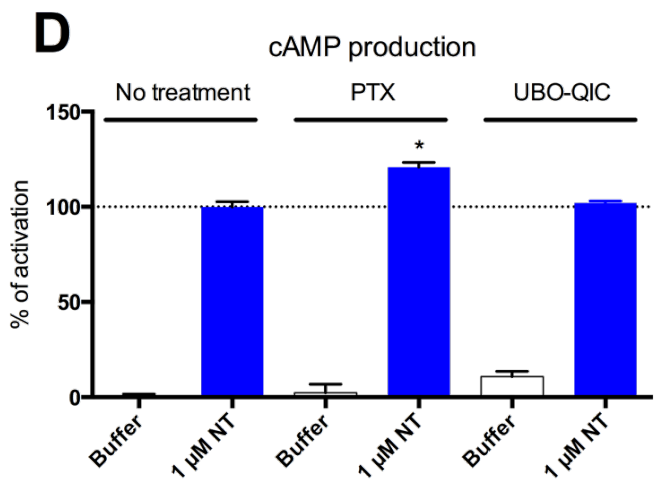

Fig. 2. Downstream $G$ protein signaling reveal functional coupling with $G \alpha_{q}, G \alpha_{s}$, and $G \alpha_{i / 0}$.

(A) Effect of increasing concentrations of NT, NT(8-13), or NN on IP1 production. (B) Effect of pretreatment with the $\mathrm{G} \alpha_{\mathrm{q}}$ inhibitor UBOQIC ( $1 \mu \mathrm{M}$ for $\left.30 \mathrm{~min}\right)$ on IP1 accumulation following stimulation with $1 \mu \mathrm{M}$ NT. (C) Effect of increasing concentrations of NT, NT(8-13), or NN on cAMP production. (D) Effect of pre-treatment with UBOQIC (1 $\mu \mathrm{M}$ for 30 min) or Pertussis toxin (PTX; 100 ng/ml, overnight) on cAMP accumulation following stimulation with $1 \mu \mathrm{M} \mathrm{NT}$. * P < 0.05 in the Mann-Whitney test compared to the activation levels without UBOQIC or PTX treatment. Each data set represents the mean of three independent experiments, which were each performed in triplicate, and is expressed as the mean \pm S.E.M.. 


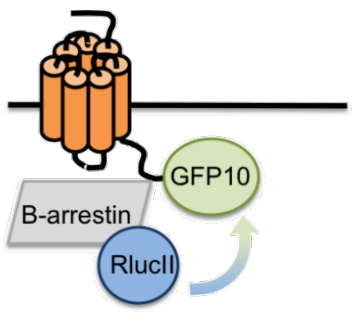

A Rlucll- $\beta$-arrestin-1/hNTS1-GFP10

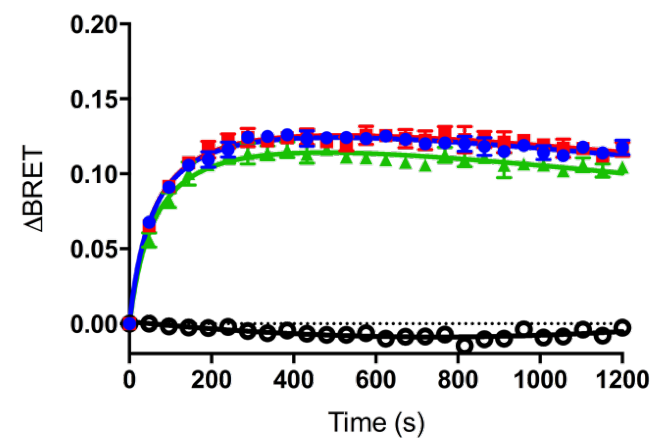

C

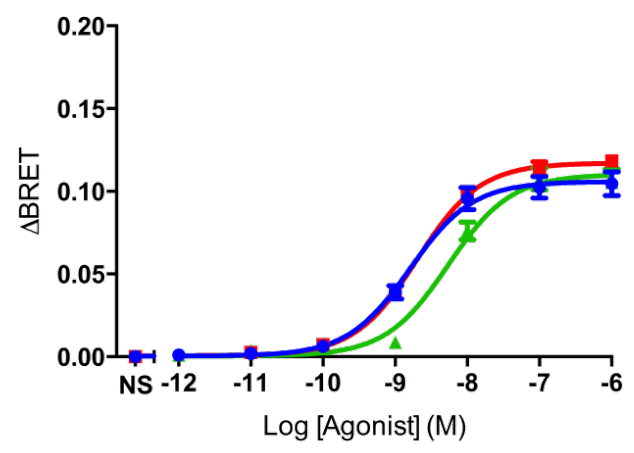

$\rightarrow$ Neurotensin 1-13

$\rightarrow$ Neurotensin 8-13

$\rightarrow$ Neuromedin N
B Rlucll- $\beta$-arrestin-2 / hNTS1-GFP10

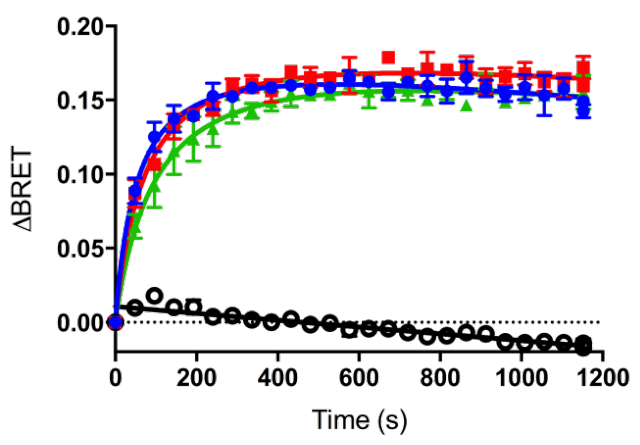

D

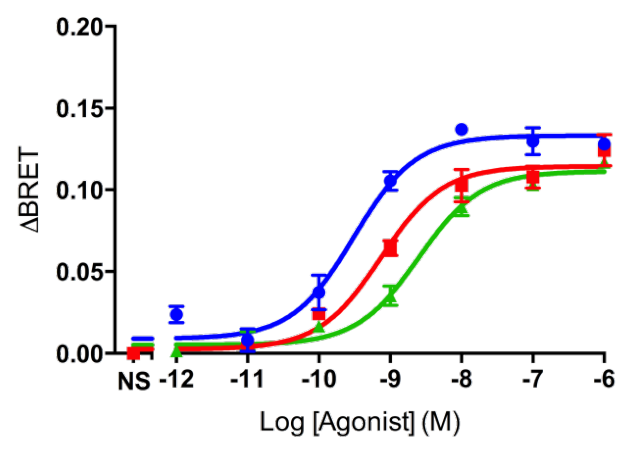

Fig. 3. NTS1 activation leads to the recruitment of $\boldsymbol{\beta}$-arrestins 1 and 2 . Kinetics of $\beta$-arrestin 1 (A) and $\beta$-arrestin 2 (B) recruitment following NTS1 activation. The black open circles represent the BRET ratio of cells stimulated only with buffer. Concentration-response curves of NT, NT(813), or NN on the recruitment of $\beta$-arrestin 1 (C) or $\beta$-arrestin 2 (D). Each data set represents the mean of three independent experiments, which were each done in triplicate, and expressed as the mean \pm S.E.M. 


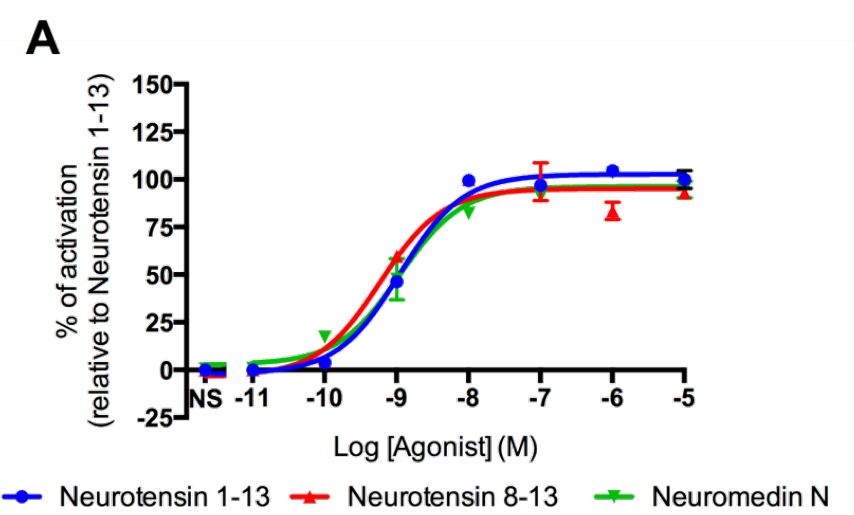

\section{C}



B

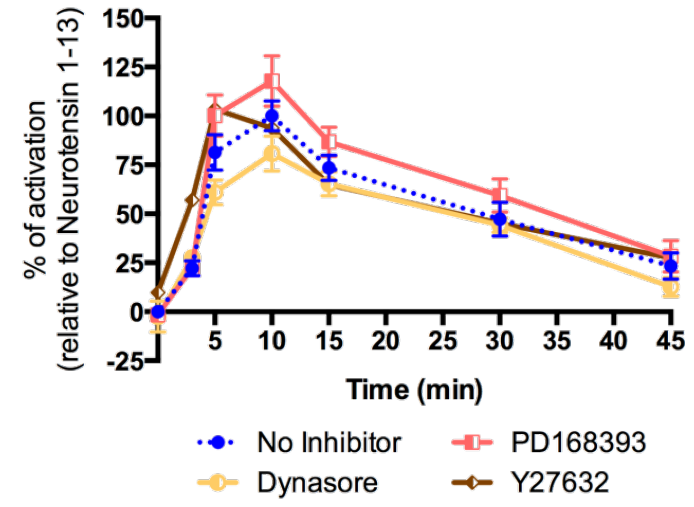

D

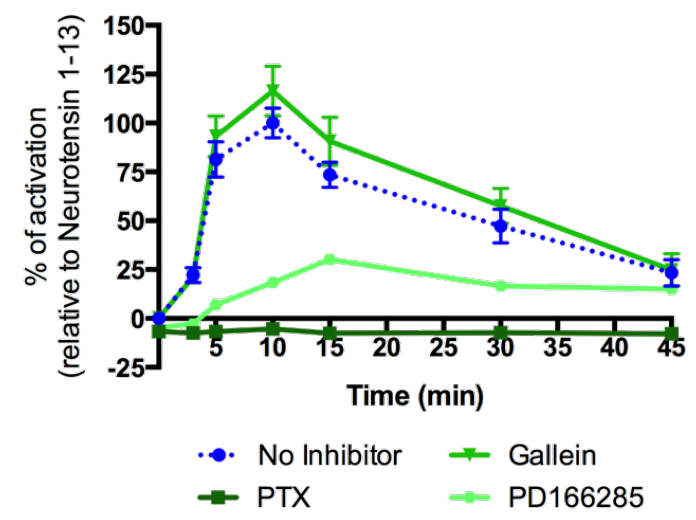

Fig. 4. NTS1 activates ERK1/2 by a $\mathbf{G} \boldsymbol{a}_{\mathrm{i} / 0^{-}}$-dependent mechanism. (A) Effect of increasing concentrations of NT, NT(8-13), or NN on ERK1/2 phosphorylation. (B-D) Effects of pretreatment on ERK1/2 phosphorylation kinetics induced by $1 \mu \mathrm{M}$ NT. (B) Pre-treatment with the EGFR inhibitor PD168393 (250 nM for $30 \mathrm{~min})$, ROCK inhibitor Y27632 (10 $\mu \mathrm{M}$ for $30 \mathrm{~min})$ or endocytosis inhibitor dynasore ( $80 \mu \mathrm{M}$ for $30 \mathrm{~min})$. (C) Pre-treatment with the $\mathrm{G} \alpha_{\mathrm{q}}$ blocker, UBOQIC (1 $\mu \mathrm{M}$ for $30 \mathrm{~min})$ or PKC inhibitor Gö6983 (1 $\mu \mathrm{M}$ for $30 \mathrm{~min})$. (D) Pre-treatment with pertussis toxin (PTX; $100 \mathrm{ng} / \mathrm{ml}$, overnight), $\mathrm{G} \beta / \gamma$-signaling inhibitor gallein (20 $\mu \mathrm{M}$ for $30 \mathrm{~min}$ ) or c-Src inhibitor PD166285 (1 $\mu \mathrm{M}$ for $30 \mathrm{~min})$. Each data set represents the mean of four independent experiments, which were each performed in duplicate, and is expressed as the mean \pm S.E.M.

(C) 2017. This manuscript version is made available under the CC-BY-NC-ND 4.0 license http://creativecommons.org/licenses/by-nc-nd/4.0/ 
A

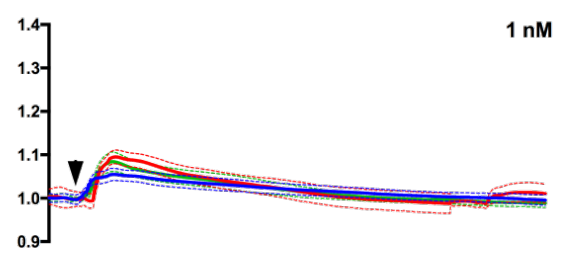

B
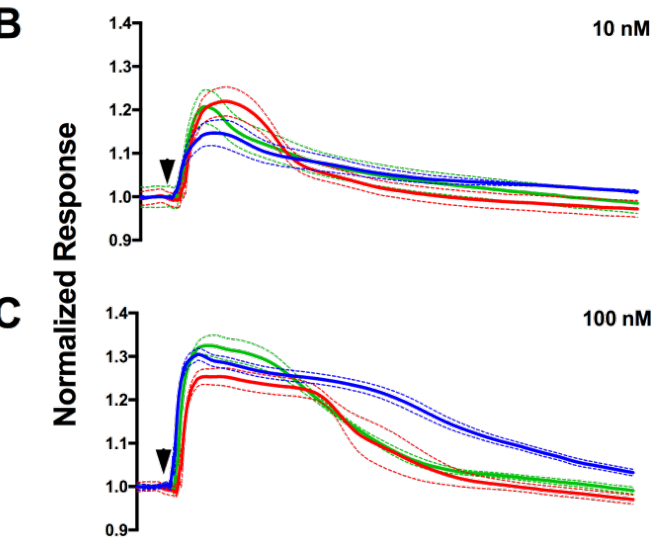

D

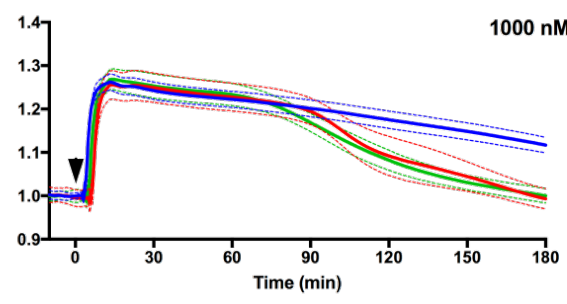

E
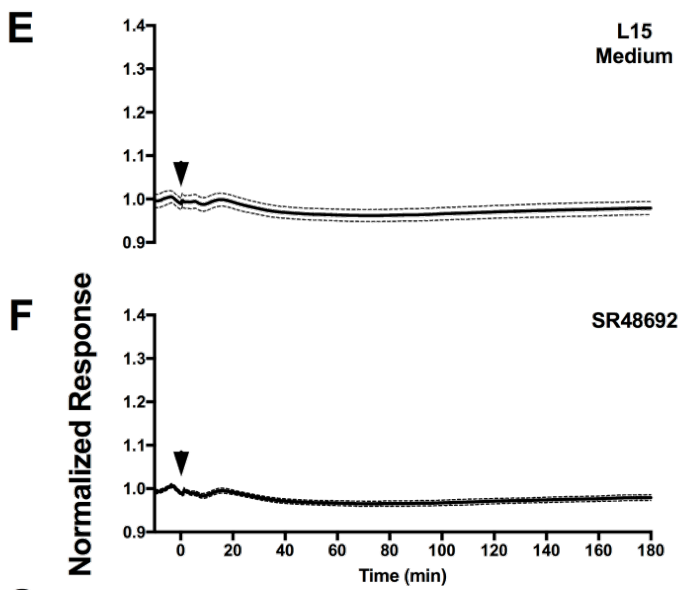

G

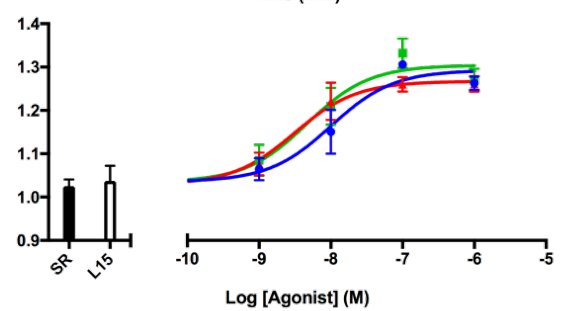

NT $\square$ NT(8-13)

Fig. 5. Effect of NTS1 activation on the resistivity of a cell monolayer. (A-F) Dynamic mass redistribution kinetics assessed by cell monolayer impedance. (A-D) Normalized response of CHO-hNTS1 cells stimulated with (A) $1 \mathrm{nM}$, (B) $10 \mathrm{nM}$, (C) $100 \mathrm{nM}$, and (D) $1000 \mathrm{nM}$ of NT (blue line), NT(8-13) (red line), or NN (green line). (E) Normalized response of CHO-hNTS1 cells stimulated with L15 medium. (F) Normalized response of CHO-hNTS1 cells stimulated with 10 $\mu \mathrm{M}$ of the NTS1 antagonist SR48692. (G) Effect of increasing concentrations of NT, NT(8-13), or NN on the whole-cell integrated response. The arrows on each graph represent the injection time of the compound. The dotted lines represent the S.E.M. values. Each data set represents the mean of three independent experiments, which were each performed in duplicate, and is expressed as the mean \pm S.E.M.. 


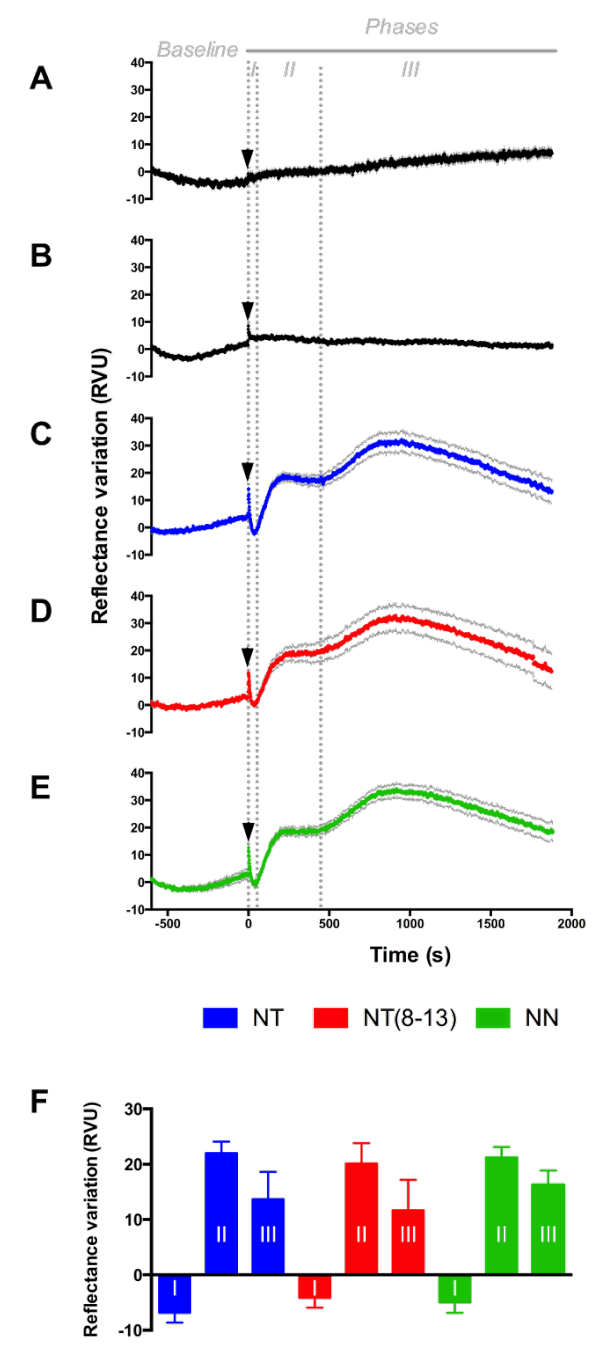

Fig. 6. Effect of NTS1 activation on the whole-cell integrated response monitored by SPR.

(A-F) Dynamic mass redistribution kinetics assessed by SPR. (A) Reflectance variation of CHOK1 stimulated with NT (1 $\mu \mathrm{M})$. Reflectance variation of CHO-hNTS1 stimulated with (B) L15 medium, (C) NT (1 $\mu \mathrm{M})$, (D) NT(8-13) $(1 \mu \mathrm{M})$ and (E) NN $(1 \mu \mathrm{M})$. The arrows on each graph represent the injection time of the compound. The gray dotted lines represent the S.E.M. values. (F) Reflectance variation in the RVU of phases I, II and III for each agonist. No significant differences were found between NT and NT(8-13) or NN on the Kruskal-Wallis test followed by Dunn's post hoc test. Each data set represents the mean of 6-8 independent experiments and is expressed as the mean \pm S.E.M.. 


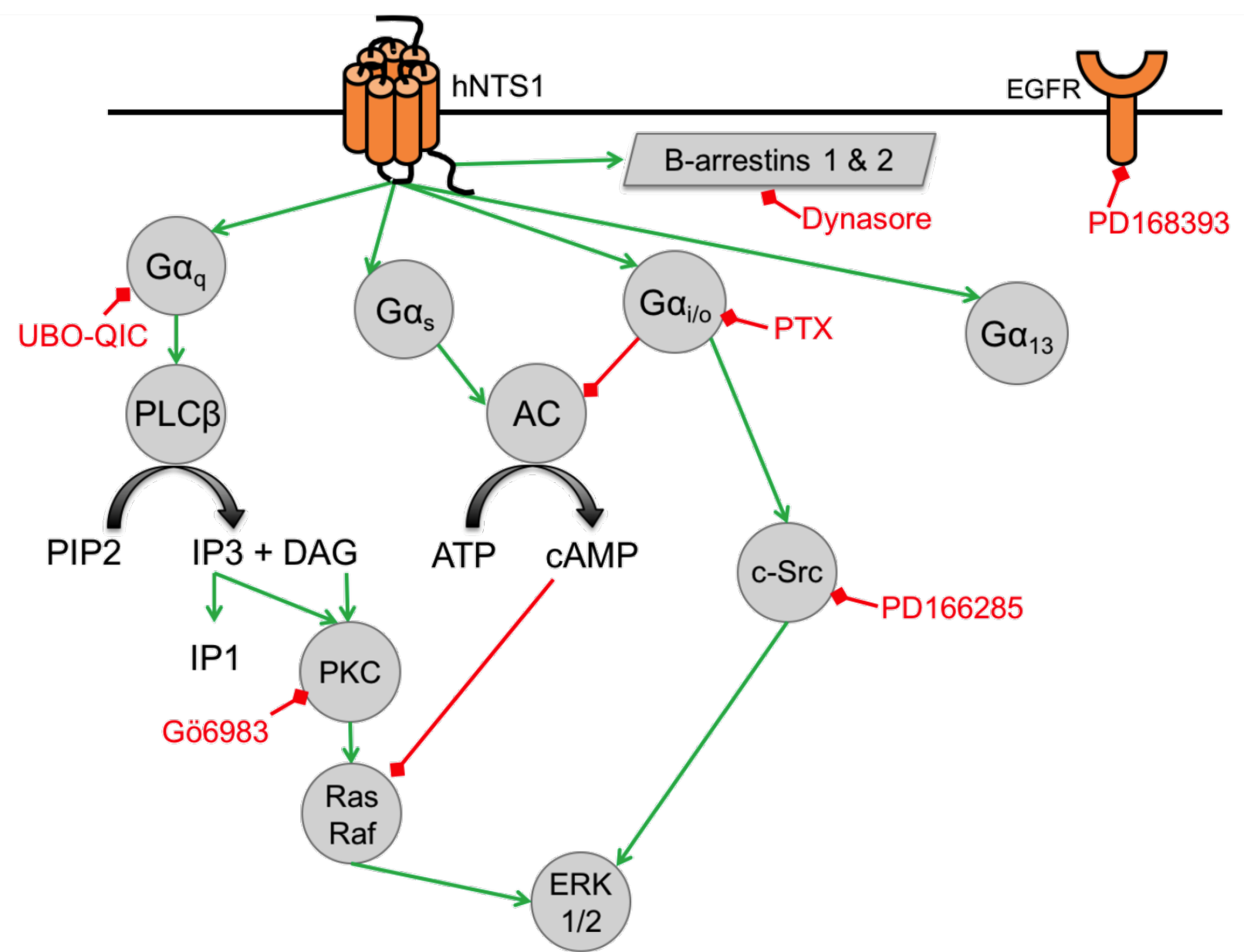

Fig. 7. Proposed signaling signature of hNTS1 following activation by NT, NT(8-13), or NN.

Following its activation by either NT, NT(8-13), or NN, hNTS1 functionally couples to $\mathrm{G} \alpha_{\mathrm{q}}, \mathrm{G} \alpha_{13}$, $\mathrm{G} \alpha_{\mathrm{i} / \mathrm{o}}$, and $\mathrm{G} \alpha_{\mathrm{s}}$ and promotes the recruitment of $\beta$-arrestins 1 and 2. Furthermore, we demonstrated that in our cellular model, NTS1 was able to induce ERK1/2 phosphorylation via $\mathrm{G} \alpha_{\mathrm{q}^{-}}$and $\mathrm{G} \alpha_{\mathrm{i} / \mathrm{o}^{-}}$ dependent mechanisms. Our results showed that $\mathrm{G} \alpha_{\mathrm{q}}$-dependent signaling is involved in the late ERK1/2 response, whereas $\mathrm{G} \alpha_{\mathrm{i} / \mathrm{o}}$ signaling via c-Src is responsible for the rapid increase in ERK1/2 phosphorylation. The stimulatory pathways are shown by the green arrows, and the red-squared arrows represent the inhibitory pathways and the inhibitors used in this study. 
This is the accepted (postprint) version of the following article: Besserer-Offroy É, et al. (2017). Eur J Pharmacol. doi: 10.1016/j.ejphar.2017.03.046, which has been accepted and published in its final form at http://www.sciencedirect.com/science/article/pii/S0014299917302157

Table 1: Peptide sequence of NT, NT(8-13) and NN

\section{Compound}

Neurotensin

Neurotensin (8-13)

Neuromedin $\mathrm{N}$
Sequence

pGlu-Leu-Tyr-Glu-Asn-Lys-Pro-Arg-Arg-Pro-Tyr-Ile-Leu-COOH

$\mathrm{H}_{2} \mathrm{~N}$ - Arg-Arg-Pro-Tyr-Ile-Leu-COOH

$\mathrm{H}_{2} \mathrm{~N}-$ Lys-Ile-Pro-Tyr-Ile-Leu-COOH 
This is the accepted (postprint) version of the following article: Besserer-Offroy É, et al. (2017). Eur J Pharmacol. doi: 10.1016/j.ejphar.2017.03.046, which has been accepted and published in its final form at http://www.sciencedirect.com/science/article/pii/S0014299917302157

Table 2: EC $_{50}$ values for NT, NT(8-13) and NN on hNTS1 activated signaling pathways

\begin{tabular}{|c|c|c|c|c|c|c|c|c|c|}
\hline \multirow{3}{*}{$\begin{array}{l}\text { Pathway } \\
\qquad G \alpha_{q}\end{array}$} & \multicolumn{9}{|c|}{$\mathrm{EC}_{50}, \mathrm{nM}$} \\
\hline & \multicolumn{3}{|c|}{ Neurotensin,NT } & \multicolumn{3}{|c|}{ Neurotensin $8-13, \mathrm{NT}(8-13)$} & \multicolumn{3}{|c|}{ Neuromedin N, NN } \\
\hline & 1.84 & \pm & 0.29 & 1.92 & \pm & 0.32 & 1.89 & \pm & 0.34 \\
\hline$G \alpha_{i 1}$ & 5.83 & \pm & 6.32 & 2.36 & \pm & 3.40 & 6.64 & \pm & 8.43 \\
\hline$G \alpha_{O A}$ & 3.44 & \pm & 1.26 & 4.12 & \pm & 1.56 & 3.37 & \pm & 1.37 \\
\hline$G \alpha_{13}$ & 3.78 & \pm & 1.37 & 3.01 & \pm & 1.36 & 4.62 & \pm & 2.54 \\
\hline$I P_{1}$ & 0.33 & \pm & 0.05 & 2.27 & \pm & $0.34^{\mathrm{b}}$ & 0.86 & \pm & $0.16^{\mathrm{a}, \mathrm{c}}$ \\
\hline$c A M P$ & 1.32 & \pm & 0.28 & 0.79 & \pm & 0.22 & 1.54 & \pm & 0.42 \\
\hline$\beta$-arr-1 & 1.60 & \pm & 0.29 & 2.01 & \pm & 0.18 & 5.41 & \pm & $1.03^{\mathrm{b}, \mathrm{d}}$ \\
\hline$\beta$-arr-2 & 0.28 & \pm & 0.09 & 0.74 & \pm & 0.18 & 2.01 & \pm & $0.67^{b, c}$ \\
\hline$p E R K 1 / 2$ & 1.10 & \pm & 0.13 & 0.60 & \pm & 0.14 & 1.09 & \pm & 0.25 \\
\hline$D M R$ & 10.1 & \pm & 7.17 & 3.10 & \pm & 1.81 & 4.67 & \pm & 3.65 \\
\hline
\end{tabular}

(C) 2017. This manuscript version is made available under the CC-BY-NC-ND 4.0 license http://creativecommons.org/licenses/by-nc-nd/4.0/ 